\title{
The Annual Cycle of East African Precipitation
}

\author{
Wenchang Yang, Richard SeAger, AND Mark A. CANE \\ Lamont-Doherty Earth Observatory, Earth Institute, Columbia University, Palisades, New York \\ BRADFIELD LYON \\ International Research Institute for Climate and Society, Lamont-Doherty Earth Observatory, \\ Earth Institute, Columbia University, Palisades, New York
}

(Manuscript received 7 July 2014, in final form 30 October 2014)

\begin{abstract}
East African precipitation is characterized by a dry annual mean climatology compared to other deep tropical land areas and a bimodal annual cycle with the major rainy season during March-May (MAM; often called the "long rains") and the second during October-December (OND; often called the "short rains"). To explore these distinctive features, ERA-Interim data are used to analyze the associated annual cycles of atmospheric convective stability, circulation, and moisture budget. The atmosphere over East Africa is found to be convectively stable in general year-round but with an annual cycle dominated by the surface moist static energy (MSE), which is in phase with the precipitation annual cycle. Throughout the year, the atmospheric circulation is dominated by a pattern of convergence near the surface, divergence in the lower troposphere, and convergence again at upper levels. Consistently, the convergence of the vertically integrated moisture flux is mostly negative across the year, but becomes weakly positive in the two rainy seasons. It is suggested that the semiarid/arid climate in East Africa and its bimodal precipitation annual cycle can be explained by the ventilation mechanism, in which the atmospheric convective stability over East Africa is controlled by the import of low MSE air from the relatively cool Indian Ocean off the coast. During the rainy seasons, however, the off-coast sea surface temperature (SST) increases (and is warmest during the long rains season) and consequently the air imported into East Africa becomes less stable. This analysis may be used to aid in understanding overestimates of the East African short rains commonly found in coupled models.
\end{abstract}

\section{Introduction}

East Africa (the region of $10^{\circ} \mathrm{S}-12^{\circ} \mathrm{N}, 30^{\circ}-52^{\circ} \mathrm{E}$, especially the eastern land areas) has experienced an increased frequency of droughts in recent years, primarily due to the decline of rainfall during the March-May (MAM) "long rains" (a term used in Kenya-TanzaniaUganda; also called "belg" or "small rains" in Ethiopia and "Gu" in Somalia), threatening the lives of millions of people in this hydrologically and politically vulnerable region (FEWS NET 2011; Lyon and DeWitt 2012). Various mechanisms have been proposed for this long rains drying trend. Williams and Funk (2011) related it to the westward extension of the Indo-Pacific warm pool

Corresponding author address: Wenchang Yang, LamontDoherty Earth Observatory, Columbia University, 61 Route 9W, Palisades, NY 10964.

E-mail: wyang@ldeo.columbia.edu and associated Walker circulation while Lyon and DeWitt (2012) and Lyon et al. (2014) linked it to a shift of sea surface temperature (SST) over the Pacific basin to a La Niña-like pattern, occurring around 1998-99. A recent study (Yang et al. 2014) demonstrated that the East African long rains exhibit variability on decadal or longer time scales and the recent drying trend is very likely part of this Pacific-centered decadal variability. Yet droughts in recent years are unprecedented in terms of their severity over the past century.

Given the recent decline of the long rains, people are inevitably wondering what will happen in the next few decades, particularly as the climate warms due to continued anthropogenic emissions of greenhouse gases (GHGs). There is a strong consensus in model projections from the Intergovernmental Panel on Climate Change (IPCC) Fourth Assessment Report (AR4) and the more recent Coupled Model Intercomparison Project phase 5 (CMIP5; Taylor et al. 

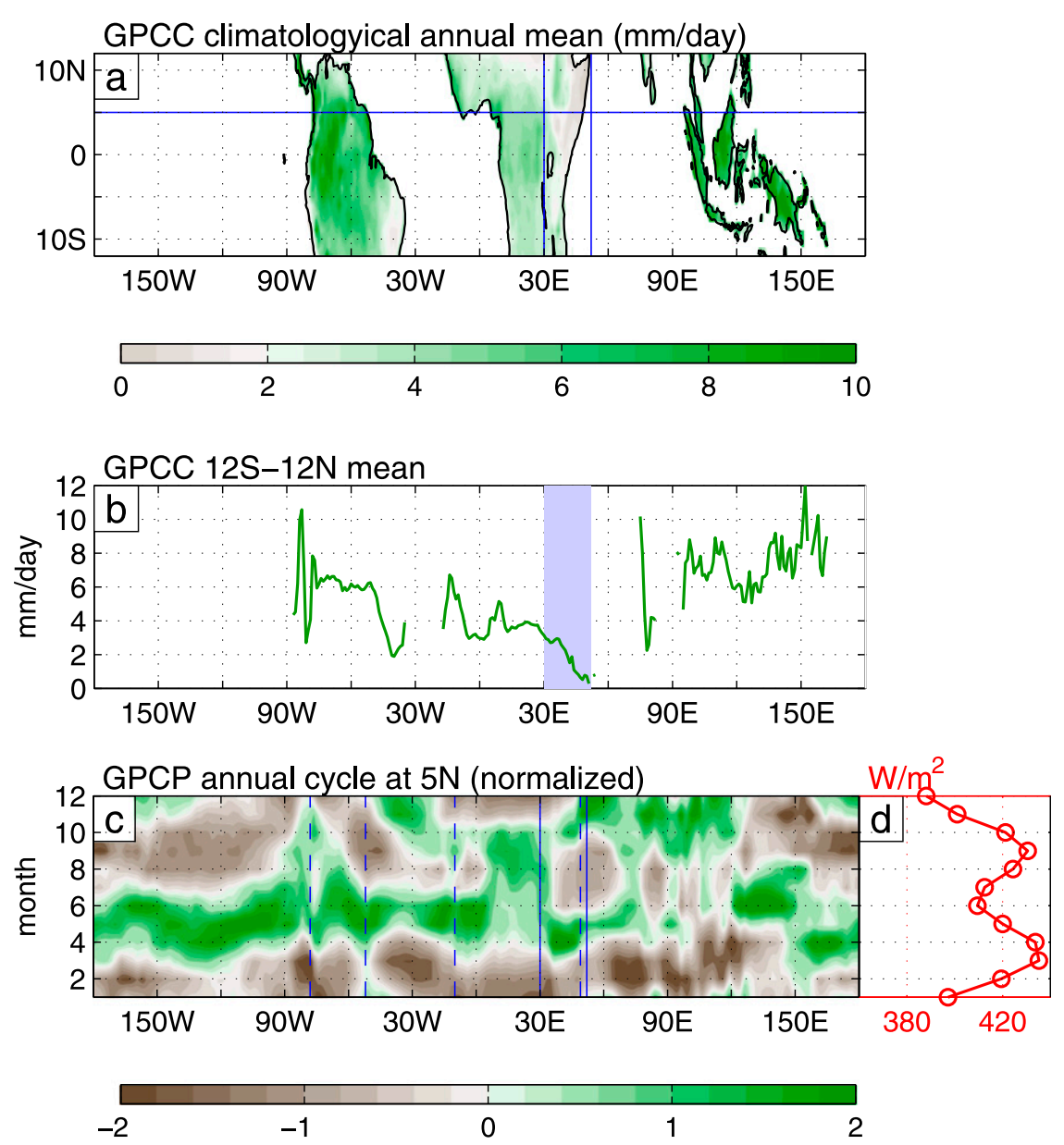

FIG. 1. (a) GPCC climatological annual mean precipitation. The vertical and horizontal blue lines are at the $30^{\circ}$ and $52^{\circ} \mathrm{E}$ longitudes and the $5^{\circ} \mathrm{N}$ latitude, respectively. (b) The $12^{\circ} \mathrm{S}-12^{\circ} \mathrm{N}$ averaged GPCC climatological annual mean in (a). The shaded rectangle marks the longitudinal range of East Africa $\left(30^{\circ}-52^{\circ} \mathrm{E}\right)$. (c) Normalized annual cycle of GPCP monthly climatology at $5^{\circ} \mathrm{N}$ (shading). Vertical blue solid lines indicate $30^{\circ}$ and $52^{\circ} \mathrm{E}$ and dashed lines indicate the longitudinal edges of South America and Africa at $5^{\circ} \mathrm{N}$. (d) Annual cycle of the monthly climatology of downward, top of the atmosphere solar radiation at $5^{\circ} \mathrm{N}$ from the NCEP-NCAR reanalysis. All climatologies are estimated based on the period of 1979-2009.

2012) that the pattern of precipitation minus evaporation $(P-E)$ will be enhanced in the warming climate (Held and Soden 2006; Seager et al. 2010; Laîné et al. 2014), which implies that the East African long rains will increase as they are part of the intertropical convergence zone (ITCZ). This implies a recovery from recent dry conditions, at least in part, in the coming decades. Indeed, this is the case in the CMIP5 model projections as shown in Fig. 2b of Yang et al. (2014). However, some studies using high-resolution regional climate models forced by ensemble-mean global climate model (GCM) projections on the lateral and ocean boundaries indicate a reduction in the long rains (Vizy and Cook 2012; Cook and Vizy 2013), leaving the long rains projections more uncertain.
While GCMs display some consistency in their projections of East African precipitation, the models' capabilities in simulating the observed climatology and temporal variability are less clear. By examining the performance of both SST-forced models and the coupled models used in the CMIP5 historical experiment in simulating the East African long rains, Yang et al. (2014) showed that although some of the SST-forced models are able to capture the observed decadal variability of the long rains, the coupled models, which are used for the twenty-first century climate projections, generally fail to capture the correct long rains-SST relationship. Moreover, the coupled models misrepresent the East African precipitation annual cycle by overestimating rainfall during the October-December (OND) "short 
rains," as was also reported for the CMIP3 coupled models (Anyah and Qiu 2012).

To understand the discrepancy between the model simulations and observations, we first need to better understand the observed East African precipitation climatological annual cycle. This has drawn little attention in the past compared to interannual variability but is a very important issue and the motivation of this study. It is also of interest to explain why East Africa is in general semiarid but has a bimodal annual cycle of precipitation. In this paper, we investigate the atmospheric thermal conditions, circulation, and moisture budget associated with the annual cycle of precipitation in this region and try to address the following questions: Why is deep tropical East Africa largely semiarid or arid in terms of annual mean rainfall (Trewartha 1961; Nicholson 1996)? Why are there two rainy seasons? What atmospheric environment conditions set the difference between the rainy seasons and the dry seasons? What explains the difference between the two rainy seasons? Why are the long rains stronger than the short rains? The remainder of this paper is organized as follows: Section 2 describes the data used in the study; section 3 briefly reviews the observed precipitation and topography in East Africa; analyses of the atmospheric thermal condition, atmospheric circulation, and moisture budget are presented in sections 4,5 , and 6 , respectively; and the main conclusions of the paper and associated discussion are provided in section 7.

\section{Data}

For precipitation, we use version 6 of Global Precipitation Climatology Centre (GPCC) monthly precipitation (Rudolf et al. 2010), which is a gauge-based, $0.5^{\circ}$ longitude $\times 0.5^{\circ}$ latitude gridded global land surface dataset for the period 1901-2010 available online (http:// iridl.ldeo.columbia.edu/expert/SOURCES/.WCRP/.GCOS/. GPCC/.FDP/.version6/.0p5/.prcp/). For comparison, we also use version 2.2 of the Global Precipitation Climatology Project (GPCP) monthly precipitation dataset from 1979 to 2010 (Huffman et al. 2009), which combines gauge observations and satellite data into $2.5^{\circ}$ longitude $\times$ $2.5^{\circ}$ latitude global grids and is available online (http:// iridl.ldeo.columbia.edu/expert/SOURCES/.NASA/. GPCP/.V2p2/.satellite-gauge/.prcp/). The observed sea surface temperature is from version $3 b$ of the NOAA National Climate Data Center (NCDC) Extended Reconstructed Sea Surface Temperature (ERSST; Smith et al. 2008), which is a globally gridded monthly dataset with a spatial resolution of $2^{\circ}$ longitude $\times 2^{\circ}$ latitude from 1854 to the present (available from http://iridl.ldeo.

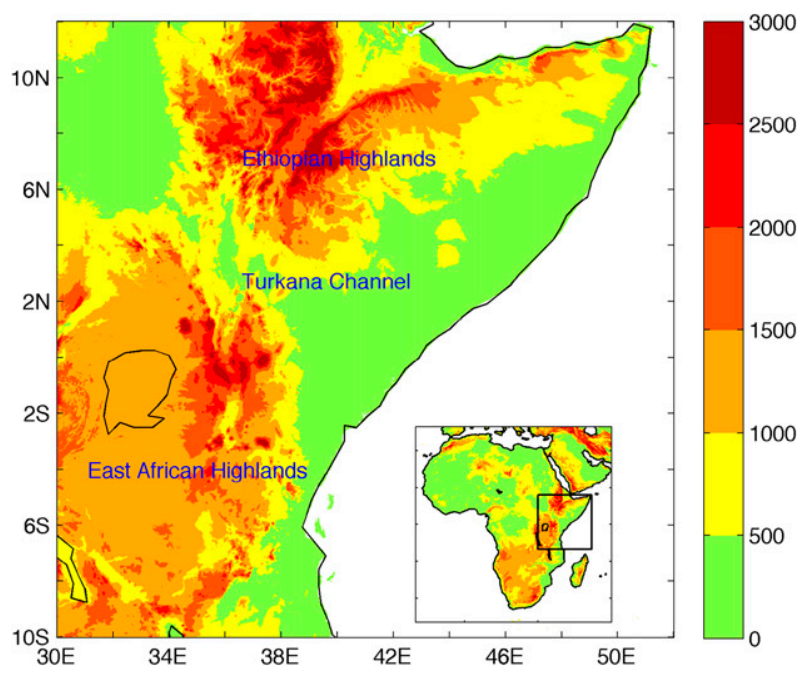

FIG. 2. Topographic elevation map (m) of East Africa. The insert shows the topographic elevation for all of Africa and a box indicating the East African region of focus in this paper.

columbia.edu/expert/SOURCES/.NOAA/.NCDC/. ERSST/.version3b/.sst/).

To estimate the thermal conditions, circulation and moisture budget, we use the Interim European Centre for Medium-Range Weather Forecasts (ECMWF) ReAnalysis (ERA-Interim) (Dee et al. 2011), which covers the post-1979 period and is the latest of the ECMWF reanalyses. ERA-Interim is generally considered to be improved in many aspects compared to its precursor, the 40-yr ECMWF Re-Analysis (ERA-40; Berrisford et al. 2011). In this paper, all seasonal climatologies and annual cycles are computed based on a 1979-2009 base period with the seasons defined as: winter dry season [January-February (JF)]; the long rains season (MAM), the summer dry season [June-September (JJAS)] and the short rains season (OND). These definitions follow the largely bimodal precipitation annual cycle found over much of this region.

\section{Precipitation and topography}

The uniqueness of East African precipitation can be seen from Fig. 1. While most tropical lands have a wet annual climatology, much of East Africa is dry with precipitation less than $2 \mathrm{~mm} \mathrm{day}^{-1}$ (Fig. 1a), consistent with a previous study [e.g., Fig. 16.7 in Nicholson (2011), p. 299). Some regions (including the western and eastern coastal areas of South America between $0^{\circ}$ and $12^{\circ} \mathrm{S}$ and the northern African interior around $10^{\circ} \mathrm{N}$ ) also have a precipitation climatology of less than $2 \mathrm{mmday}^{-1}$, but the area is not comparable in scale with East Africa. The $12^{\circ} \mathrm{S}-12^{\circ} \mathrm{N}$ GPCC climatological annual mean precipitation as shown in Fig. 1b demonstrates that tropical 


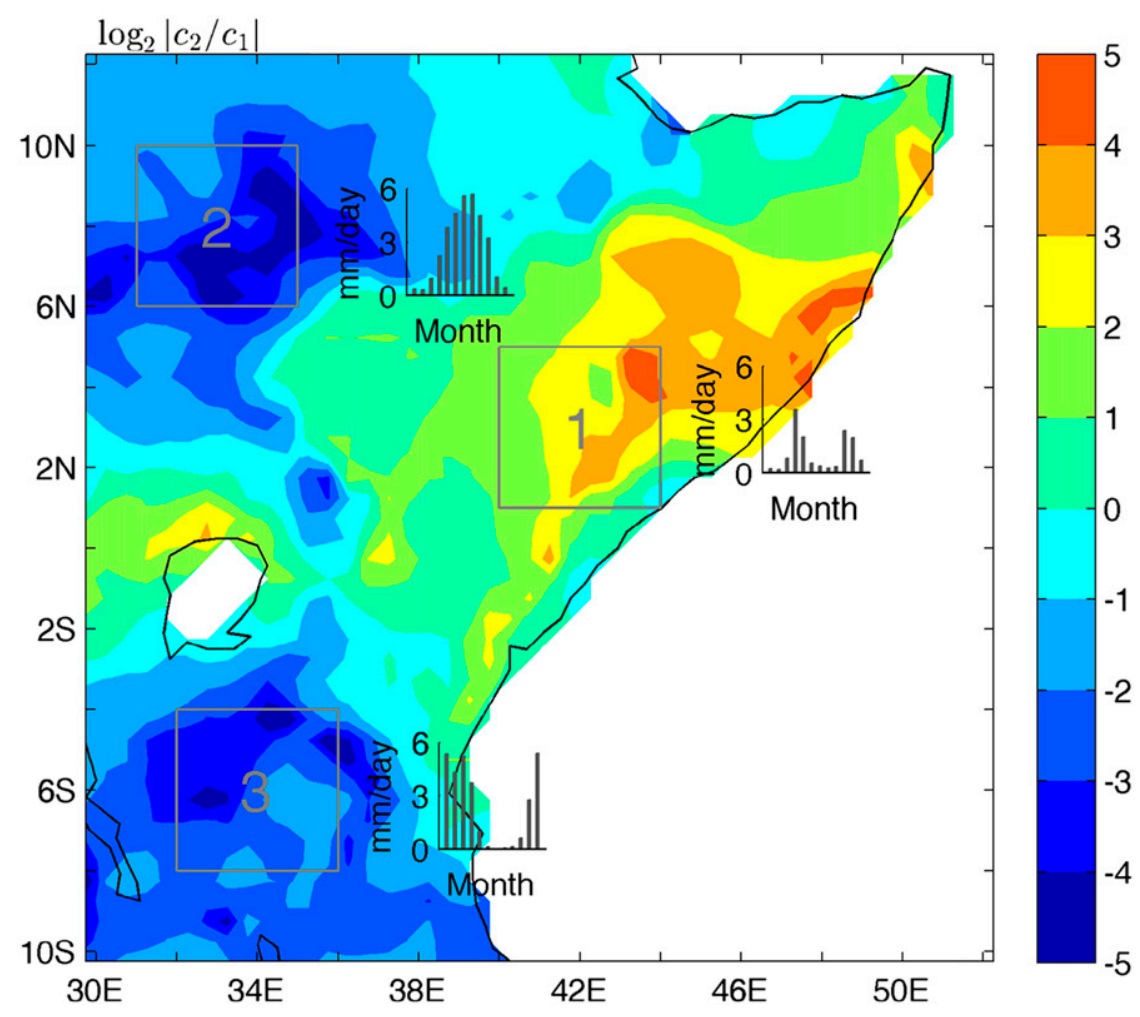

FIG. 3. Distribution of precipitation (from GPCC) annual cycle type, which is measured by $\log _{2}\left|c_{2} / c_{1}\right|$, where $c_{1}$ and $c_{2}$ are the Fourier harmonics of the annual period and the semiannual period, respectively. Positive (negative) values occur when the semiannual (annual) period mode dominates. Boxes with gray numbers 1,2 , and 3 in their centers have ranges of $1^{\circ}-5^{\circ} \mathrm{N}$, $40^{\circ}-44^{\circ} \mathrm{E} ; 6^{\circ}-10^{\circ} \mathrm{N}, 31^{\circ}-35^{\circ} \mathrm{E}$; and $4^{\circ}-8^{\circ} \mathrm{S}, 32^{\circ}-36^{\circ} \mathrm{E}$, respectively. Bar graphs next to the boxes show the annual cycle of precipitation averaged by month over the corresponding boxes.

land generally has less precipitation in Africa than South America and the Maritime Continent, and East Africa is even drier than western Africa. The eastern Horn of Africa region is the precipitation minimum at all longitudes.

Figure 1c (shading) shows the normalized annual cycle of GPCP monthly climatology at $5^{\circ} \mathrm{N}$ (the latitude is denoted by a blue horizontal line in Fig. 1a). East African longitudes at this latitude have a distinctive bimodal annual precipitation cycle, with the major and minor peaks in April and October, respectively. Other longitudes over land generally only have a single peak, although the peak months differ for different longitudes. For example, the annual cycle of precipitation over South America largely peaks between May and July, whereas for the African interior longitudes the peaks are between July and October. It should be noted that the western end of Africa at $5^{\circ} \mathrm{N}$ does have a bimodal annual cycle, but the two peaks are often viewed as one rainy season that is interrupted by the so-called midsummer drought (Karnauskas et al. 2013). Figure 1d shows the annual cycles of downward, top of the atmosphere
(TOA) solar radiation at $5^{\circ} \mathrm{N}$ (red line with circles). The two peaks of the solar radiation annual cycle (March and September) lead the two corresponding East African precipitation peaks by one month. The solar radiation is also greater in the boreal summer season than the winter season but precipitation over East African longitudes in boreal summer is comparable with or less than that in the winter, suggesting that it is difficult to simply attribute the East African precipitation annual cycle directly to the incoming solar radiation forcing.

One of the major factors responsible for the climate in East Africa is the complex topography (Nicholson 1996; Lyon 2014). Figure 2 shows the topographic elevation map of East Africa. The topography of East Africa can be roughly characterized by the coastal plain to the east and the generally north-south orientation of the interior highlands. The highlands to the north (the Ethiopian highlands) and to the south (the East African highlands) are separated by a narrow gap (the Turkana channel), which connects the area of relatively low topography to the northwest and the eastern coastal plain. Local 
variations in climate over East Africa are greatly influenced by these topographical features as they play an important role in the low-level atmospheric circulations and moisture transport (Findlater 1969; Kinuthia and Asnani 1982; Kinuthia 1992).

The annual cycle of precipitation over much of East Africa shows a bimodal distribution although in some regions a unimodal distribution dominates. To show the spatial distribution of the precipitation annual cycle types, the Fourier harmonics of the precipitation annual cycle are estimated in the GPCC data at each grid point and the ratio $\left|c_{2} / c_{1}\right|$ of the amplitude of the semiannual-period harmonic $c_{2}$ (representing the bimodal distribution) to the annual-period harmonic $c_{1}$ (representing the unimodal distribution) is calculated. Figure 3 shows the spatial distribution of the binary logarithm of this ratio so that positive (negative) values occur where the bimodal (unimodal) distribution dominates. It can be seen that the bimodal distribution dominates to the east of the highlands and near the equator while the unimodal distribution dominates over the southern and northwestern parts of the study domain. The average precipitation annual cycle over box 1 (shown to the right of the box) has the typical two rainy seasons in East Africa: the long rains in MAM and the short rains in OND. In contrast, boxes 2 and 3 only have one rainy season: the precipitation peaks during boreal summer over box 2 and during austral summer over box 3 , both showing a typical monsoonal character.

An even simpler way to identify the bimodal areas from the unimodal areas is to compare the precipitation rate during the long rains season $\left(\mathrm{pr}_{\mathrm{MAM}}\right)$ with that during the boreal summer $\left(\mathrm{pr}_{\mathrm{JJAS}}\right)$ and during the boreal winter $\left(\mathrm{pr}_{\mathrm{JF}}\right)$ and select the areas satisfying the criteria: $\mathrm{pr}_{\mathrm{MAM}}>\mathrm{pr}_{\mathrm{JJAS}}$ and $\mathrm{pr}_{\mathrm{MAM}}>\mathrm{pr}_{\mathrm{JF}}$. The results are highlighted as gray shadings in the mini panel in the middle of Fig. 4 and mainly cover the areas to the east of the highlands, a similar pattern to that with the positive values in Fig. 3. Hereafter the term "East Africa" is used to refer to the gray-shaded areas in the inset of Fig. 4 when an area average is implied. The area-averaged precipitation annual cycle over the shaded area is shown in Fig. 4 and has the typical bimodal annual precipitation cycle of East Africa. Both the GPCC and GPCP precipitation datasets show similar results, with wettest conditions during the long rains season (area average precipitation $>2 \mathrm{~mm} \mathrm{day}^{-1}$ ), relatively wet conditions during the short rains season (precipitation between 1.5 and $2.5 \mathrm{~mm} \mathrm{day}^{-1}$ ), and comparatively dry conditions during other seasons (precipitation $>1.5 \mathrm{~mm} \mathrm{day}^{-1}$ ). April is the wettest month of the year, with precipitation close to $4 \mathrm{~mm} \mathrm{day}^{-1}$.

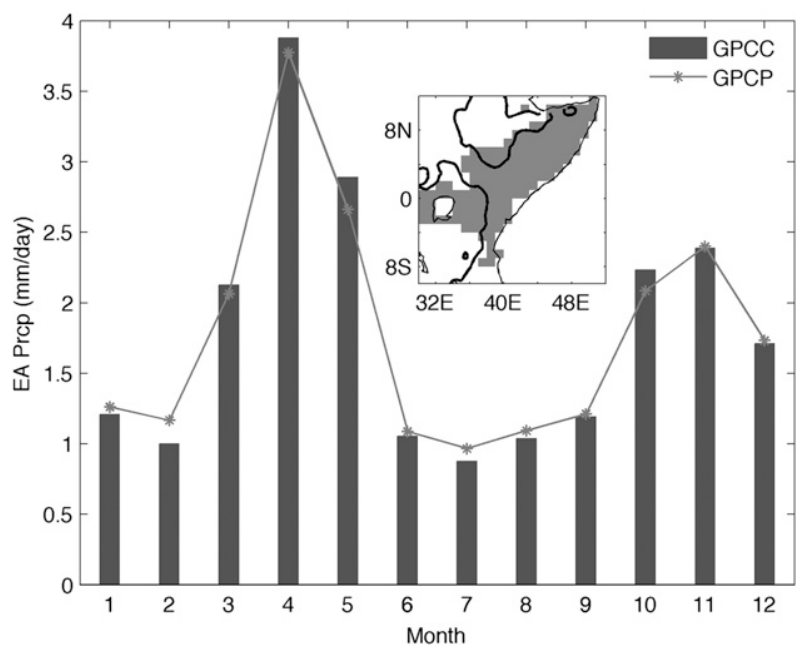

FIG. 4. The annual cycle of East African area-averaged precipitation $\left(\mathrm{mm} \mathrm{day}^{-1}\right)$ from GPCC and GPCP. The grid points to be averaged are chosen by the criteria that the precipitation rate during the long rains (MAM) is greater than that during both boreal summer (JJAS) and boreal winter (JF) so that the areas with bimodal precipitation annual cycle are focused on. The inset panel shows the areas satisfying the criteria (gray shading), which resemble the areas with positive values in Fig. 3; the thick black lines are the 1000-m topographical elevation contours.

What is the spatial distribution of precipitation during the different seasons? Figure 5 shows the seasonal climatologies of precipitation over East Africa. Months not covered by the long rains and the short rains are grouped into the boreal winter season (JF) and the boreal summer season (JJAS) as mentioned previously. During the long rains (Fig. 5b), the precipitation rate over the coastal areas to the east of the highlands peaks and in general exceeds $1 \mathrm{mmday}^{-1}$ except in the northeastern extreme of the Horn of Africa. The short rains (Fig. 5d) show a similar precipitation pattern to the long rains but with a slightly weaker magnitude. During the boreal winter season (Fig. 5a), the precipitation maxima appear over the southern extreme of the study domain, and are part of the ITCZ. The northern half of the region is generally dry except for some small areas over the highlands. During the boreal summer season (Fig. 5c), the largest rainfall amounts are found in the northwest, especially over western areas of the northern highlands, where they form the eastern reach of the West African monsoon. Moderately wet conditions are also found right on the east coast between $6^{\circ} \mathrm{S}$ and $2^{\circ} \mathrm{N}$ during JJAS, probably caused by an onshore breeze. Other regions are generally dry during this season.

Figure 5 also shows the climatological values of SSTs off the east coast and it is seen that the seasonal precipitation to the east of the highlands covaries with the 

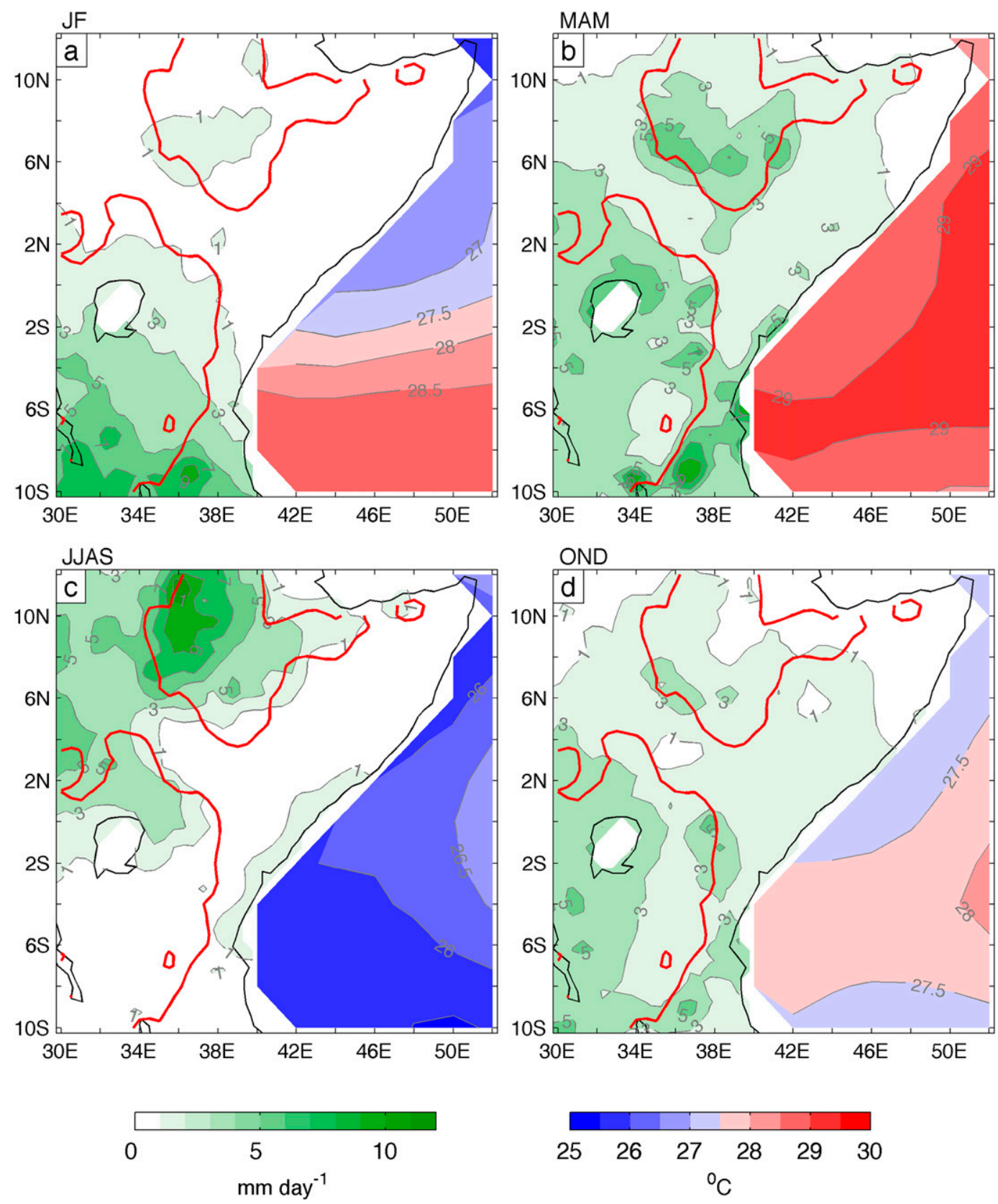

FIG. 5. Seasonal climatologies of precipitation $\left(\mathrm{mm} \mathrm{day}^{-1}\right)$ from GPCC over East Africa and SST $\left({ }^{\circ} \mathrm{C}\right)$ from ERSST off the east coast. The red lines are the smoothed contours of the 1000-m topographical elevation.

near-coast SSTs. SSTs are highest during the long rains season (greater than $28.5^{\circ} \mathrm{C}$ ) and are around $1.5^{\circ} \mathrm{C}$ cooler, yet with a similar pattern, during the short rains season. SSTs are coolest during boreal summer when the overall coastal conditions are driest. During boreal winter, a relatively strong north-south SST gradient is evident and there is an associated gradient in precipitation between the north and the south. The relationship between the East African precipitation and the near-coast SST, or the western equatorial Indian Ocean (WEIO) SST, is further demonstrated in their annual cycles in Fig. 6. Despite of imperfect month-tomonth covariation, both the precipitation and SST peak in April and have the overall lowest values during the July-September season. It is noted that the JF SSTs are as high as the November and December values, yet the JF season is as dry as the boreal summer season. This might be due to the strong north-south SST gradient in 


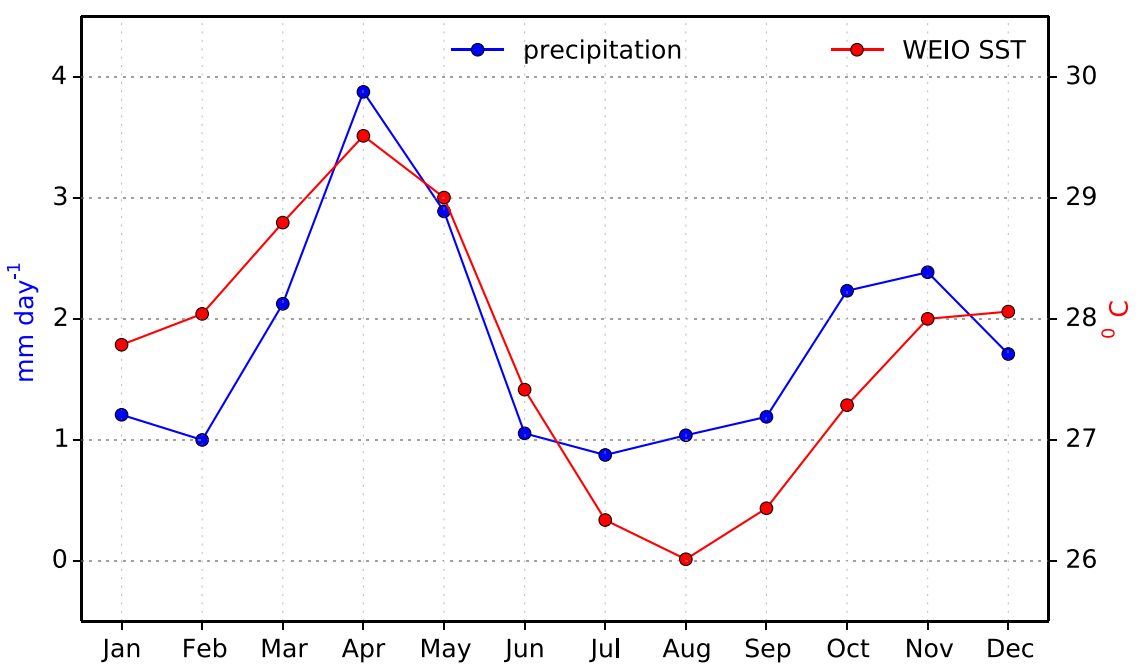

FIG. 6. East African precipitation annual cycle from GPCC (blue line) and annual cycle of SST over the western equatorial Indian Ocean (WEIO, ocean area within $10^{\circ} \mathrm{S}-10^{\circ} \mathrm{N}$ and $30^{\circ}-$ $60^{\circ} \mathrm{E}$; red line).

JF as shown in Fig. 5a: the cool SST in the north is related to the dry condition over much of East Africa while the warm SST in the south contributes to the similarly high area-averaged SST as in the OND season.

The precipitation-SST relationship suggests that SSTs might play an important role in the annual cycle of East African precipitation. Previous studies (McCreary et al. 1993; Murtugudde et al. 1996, 2007) demonstrated that both surface heat flux and ocean dynamics play import roles in the annual cycle of Indian Ocean SSTs. For example, during boreal summer, the cold SSTs off the coast of East Africa are driven by a wide range of processes including upwelling, horizontal advection, mixed layer entrainment, and latent flux (McCreary et al. 1993). These results imply that external forcings that are responsible for the East African precipitation annual cycle might be intrinsically complex.

\section{Atmospheric thermal condition}

Tropical precipitation is strongly connected with the thermal state of conditional instability (Emanuel et al. 1994). One simple measurement of this instability is the difference between the surface moist static energy (MSE; is defined as $h=c_{p} T+L q+g z$, where $c_{p}, T, L$, $q, g$, and $z$ are specific heat capacity at constant pressure, absolute air temperature, latent heat of evaporation, gravity acceleration, and the height above the surface, respectively) and the saturated MSE at $700 \mathrm{hPa}$ (denoted as $h_{s}-h_{700 \mathrm{hPa}}^{*}$ ); $700 \mathrm{hPa}$ is chosen as the first standard pressure level clearly above the boundary layer. A similar definition can also be seen in Cook and Seager (2013). Figure 7 shows the seasonal climatologies of $h_{s}-h_{700 \mathrm{PPa}}^{*}$ (which has been normalized by the heat capacity of the air at constant pressure $c_{p}$ so it has the unit of kelvin). In JF (Fig. 7a), there is a strong north-south gradient of the conditional instability seasonal climatology (colors). Most areas over the northern half of the region are also extremely stable, corresponding to the dry areas in Fig. 5a. Southern areas are less stable, favoring much wetter conditions. The north-south gradient in the seasonal climatology of stability and precipitation during JF arises mainly from a similar pattern of changes from the previous season (contours). In MAM (Fig. 7b), the stability weakens over northern areas and slightly strengthens over the extreme south, accompanied by northward expansion of the precipitation and the occurrence of the long rains as shown in Fig. 5b. In JJAS (Fig. 7c), the stability continues to weaken over the northwest monsoon area but strengthens elsewhere, resulting in a northwest-southeast gradient of stability over the region, corresponding to a similar pattern of precipitation in this season (Fig. 5c). In OND (Fig. 7d), stability strengthens over the northwest but weakens over most of the east, which is accompanied by the short rains season (Fig. 5d).

The seasonal climatologies of the conditional instability and the season-to-season changes over East Africa are dominated by the changes in surface $\operatorname{MSE}\left(h_{s}\right.$, Fig. 8) rather than the 700-hPa saturated MSE $\left(h_{700 \mathrm{HPa}}^{*}\right.$, not shown), as shown by the resemblance of Fig. 8 to Fig. 7 (colors and contours). Figure 9 shows the annual cycles of the surface MSE and the saturated MSE at $700 \mathrm{hPa}$ over the bimodal precipitation areas (shaded areas in Fig. 4). The amplitude of the surface MSE cycle 

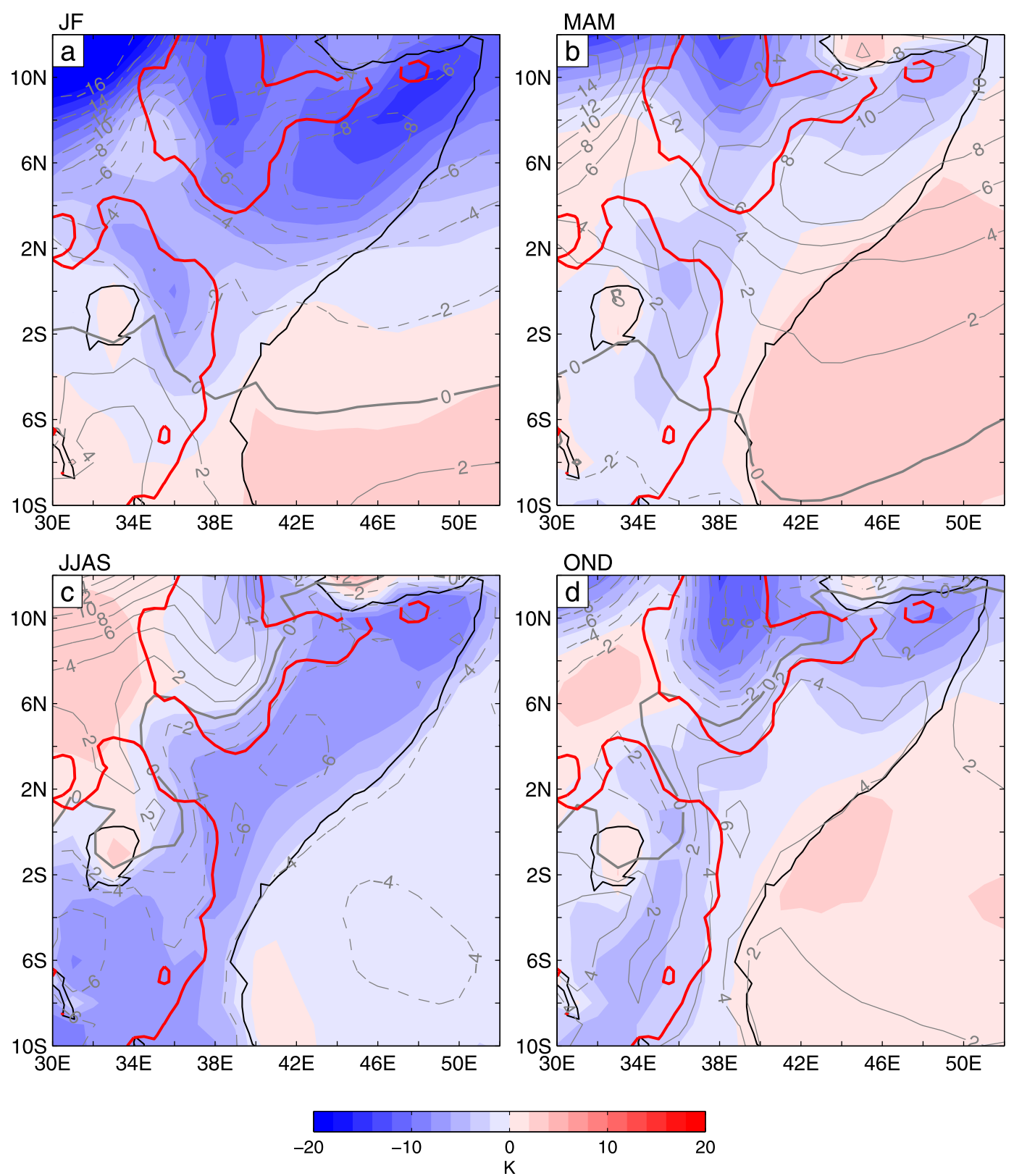

FIG. 7. Seasonal climatologies of the surface moist static energy (MSE) minus the saturated MSE at $700 \mathrm{hPa}$ (colors) and their changes from the previous season (contours), both from ERA-Interim. The MSE is normalized by the heat capacity of the air at constant pressure so that it has the unit of kelvin. The thick red lines are the contours of the 1000-m topographical elevation.

is around 3 times stronger than that of the 700-hPa saturated MSE cycle. As a result, the difference between the two (the gray line) has a pattern similar to the surface MSE. While the annual cycle of the 700-hPa saturated MSE is dominated by the annual harmonic, which probably arises from the dominance of annual harmonic of SST near the equator (Schneider 1996), the surface MSE is dominated by the semiannual harmonic, similar to the precipitation annual cycle. Large surface MSE appears during the two rainy seasons, with values during the long rains larger than for the short rains. April is the month of maximum surface MSE across the year, consistent with the maximum precipitation rate during this month (Fig. 4).

We further decompose the surface MSE into the component associated with temperature and the component associated with moisture (the component of MSE associated with geopotential height has little 

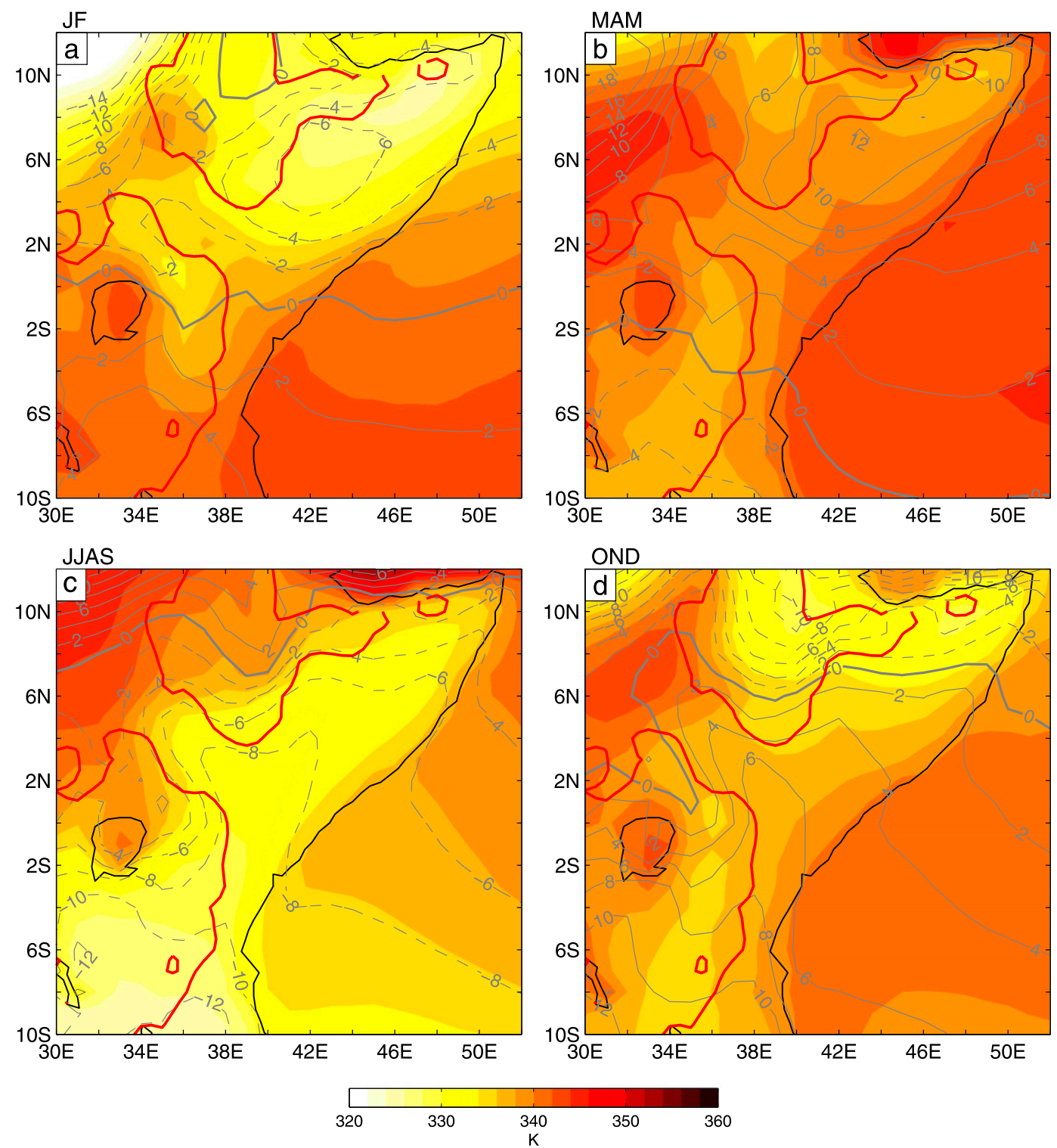

FIG. 8. As in Fig. 7, but for the surface MSE (colors) and its change from the previous season (contours) from ERAInterim.

seasonal variation and is not discussed here). The seasonal cycle of the surface MSE is dominated by the moisture component (Fig. 10) and the variation of the temperature component can largely be neglected (only around one-fifth of the moisture component and not shown here). Both the seasonal climatologies and the season-to-season changes of the moisture component of the surface MSE resemble those of the conditional instability in Fig. 7, suggesting that the annual cycle of the surface air conditional instability is largely explained by the moisture component of the surface MSE. Hence we need to explain the seasonal cycle of the moisture field across East Africa.

\section{Atmospheric circulation}

Figure 11 shows the seasonal climatologies of $10-\mathrm{m}$ winds from ERA-Interim and their divergence. During JF (Fig. 11a), the Asian winter monsoon northeasterlies prevail and bring relatively cold and dry air into East Africa from the northeast. The $10-\mathrm{m}$ winds are generally convergent to the east of the highlands, probably due to deceleration by surface friction as they penetrate inland. Yet most of the time these convergent winds are not able to bring precipitation because of the convectively stable atmosphere (as described in the previous section) as well as the shallowness of the 


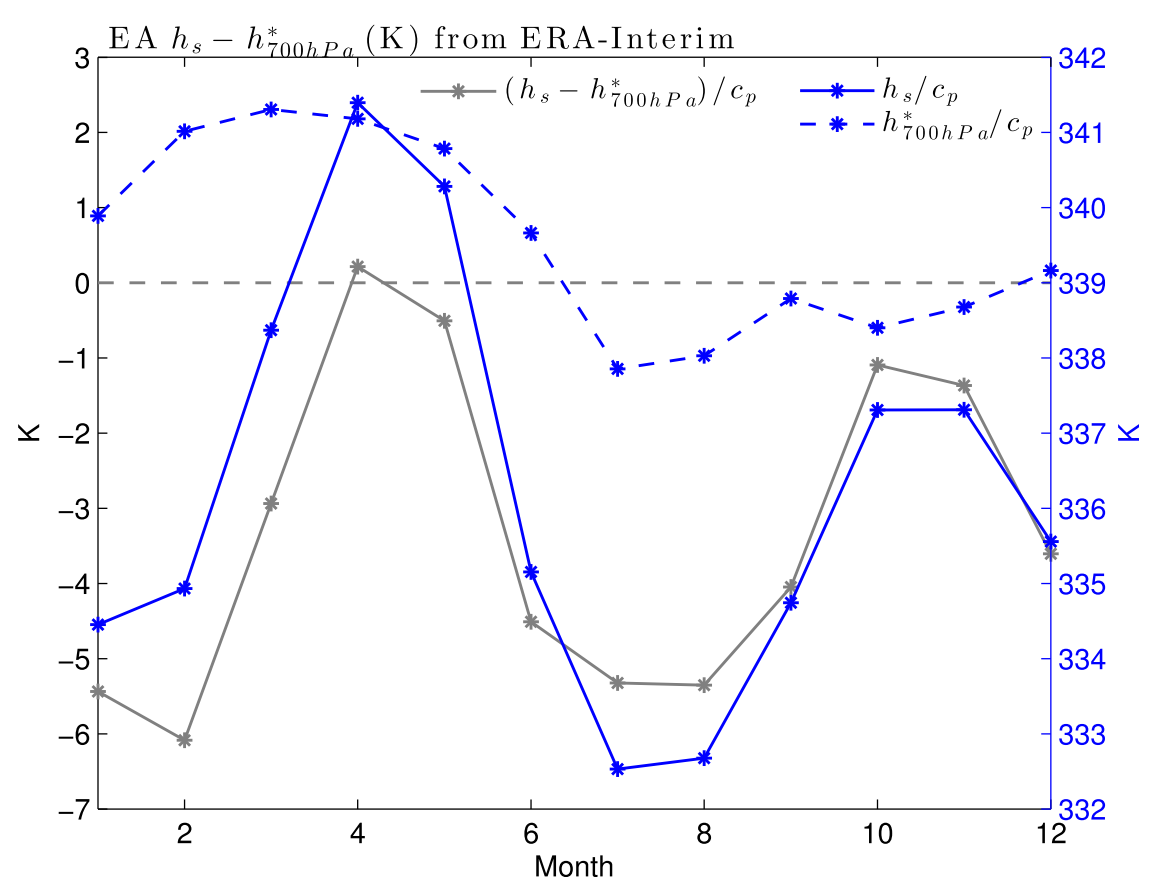

FIG. 9. Annual cycles of surface MSE (solid blue line) and the saturated MSE at 700-hPa pressure (dashed blue line) averaged over the shaded area shown in Fig. 4, and the difference between the two (solid gray line).

convergence layer (as will be presented in the next paragraph).

During MAM (Fig. 11b), southeasterlies replace the northeasterlies and bring warm and moist air from the southeast, that is, from over the southwestern Indian Ocean, where climatological SSTs are their highest of the year (Fig. 5b). The surface winds are convergent over the northeastern Horn of Africa and near the coastal land areas but become divergent near the entrance of the Turkana channel between the northern and the southern highlands, due to the easterly acceleration when going through the entrance.

Figure $11 \mathrm{c}$ shows the $10-\mathrm{m}$ winds in JJAS. The southeasterlies intensify and turn east slightly as they travel farther north, while their dynamics becomes intrinsically nonlinear (Yang et al. 2013). The low-level southerlies off the equatorial East African coast, commonly known as the East African low-level jet (Findlater 1969), are part of the Asian summer monsoon system. The $10-\mathrm{m}$ winds accelerate as they travel across eastern land areas, resulting in divergence of the wind field. It is interesting to note that even though the alongcoast component of the surface winds over eastern land areas becomes stronger in JJAS than MAM, the onshore components are comparable. However, in contrast to the long rains in MAM, land areas are extremely dry in JJAS, when SSTs off the east coast are the coldest in the annual cycle (Fig. 5c) and the air above is comparatively cold and dry, resulting in cool, dry, and stable air advecting over East Africa.

During OND (Fig. 11d), the jet weakens and the magnitude of the onshore and southerly flow south of the equator changes back to the MAM level. In general, the surface wind pattern resembles that in MAM except over the northeast, where northeasterlies or easterlies prevail in OND while southeasterlies prevail in MAM. The spatial distribution of precipitation in OND (Fig. 5d) is also similar to that in MAM (Fig. 5c) although the overall rainfall rates are slightly weaker in the short rains season (OND), possibly due to the cooler SSTs at this time.

The 850-hPa winds (Fig. 12) show a similar pattern to that at the surface. However, the divergence field is completely different from the surface, with year-round divergence over almost all land areas to the east of the highlands. The magnitude of the divergence of the wind field is stronger during the dry seasons of JF and JJAS and weaker during the wet seasons of MAM and OND, consistent with the precipitation annual cycle.

Figure 13 shows a vertical cross section of the annual cycle of the area-averaged divergence over East Africa. Although convergence appears near the surface, the low-level atmosphere immediately above is dominated by divergence across the year, especially between 850 and $700 \mathrm{hPa}$. The annual cycle also shows a bimodal distribution, with maxima appearing at the beginning of the long rains and just before the short rains. 

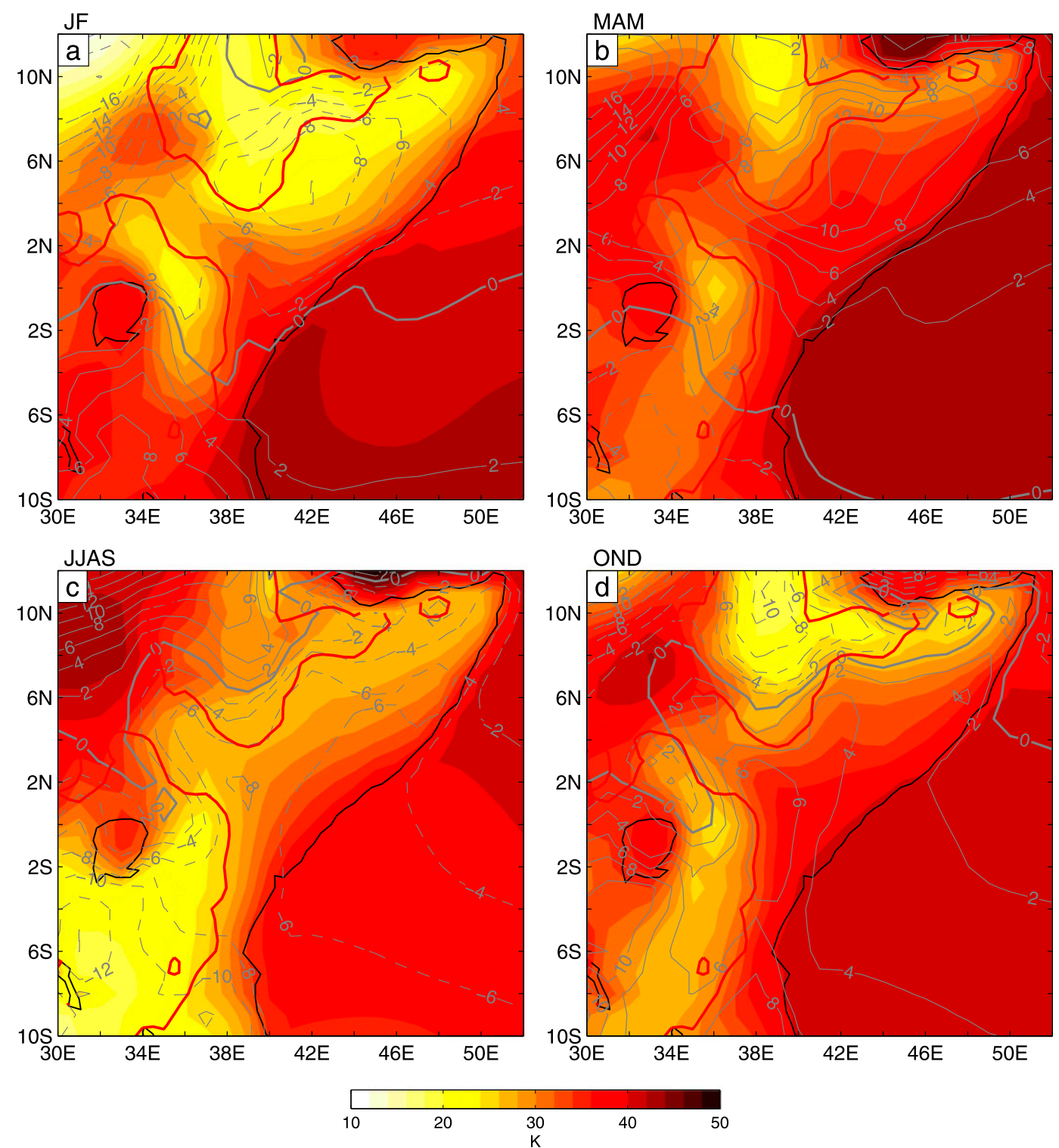

40

FIG. 10. As in Fig. 8, but for the component of MSE associated with moisture.

Accordingly, the upper-level atmosphere is dominated by convergence year-round, with maximum convergence appearing during the dry seasons and weak convergence appearing during the rainy season, in phase with the precipitation annual cycle.

Consistent with the dominance of the low-level divergence and upper-level convergence, the seasonal climatologies of the 500-hPa vertical pressure velocity (Fig. 14) are dominated by downward motions yearround, with larger values during the dry seasons and weakening during the rainy seasons. Figure 15 shows the annual cycle of the area-averaged vertical pressure velocity on different pressure levels. Although the lowlevel atmosphere is dominated by upward motion, these do not penetrate into the middle atmosphere, where the downward motions dominate, except during the long rains season. This is consistent with the divergence shown in Fig. 13. The seasonal cycles of vertical motion and divergence are consistent with that of convective instability, which derives primarily from the seasonal cycle of moist static energy of low level air.

\section{Moisture budget}

The vertically integrated moisture budget was evaluated based on 6-hourly data from ERA-Interim. The equation is the same as Eq. (13) in Seager and Henderson (2013) and is rewritten here: 

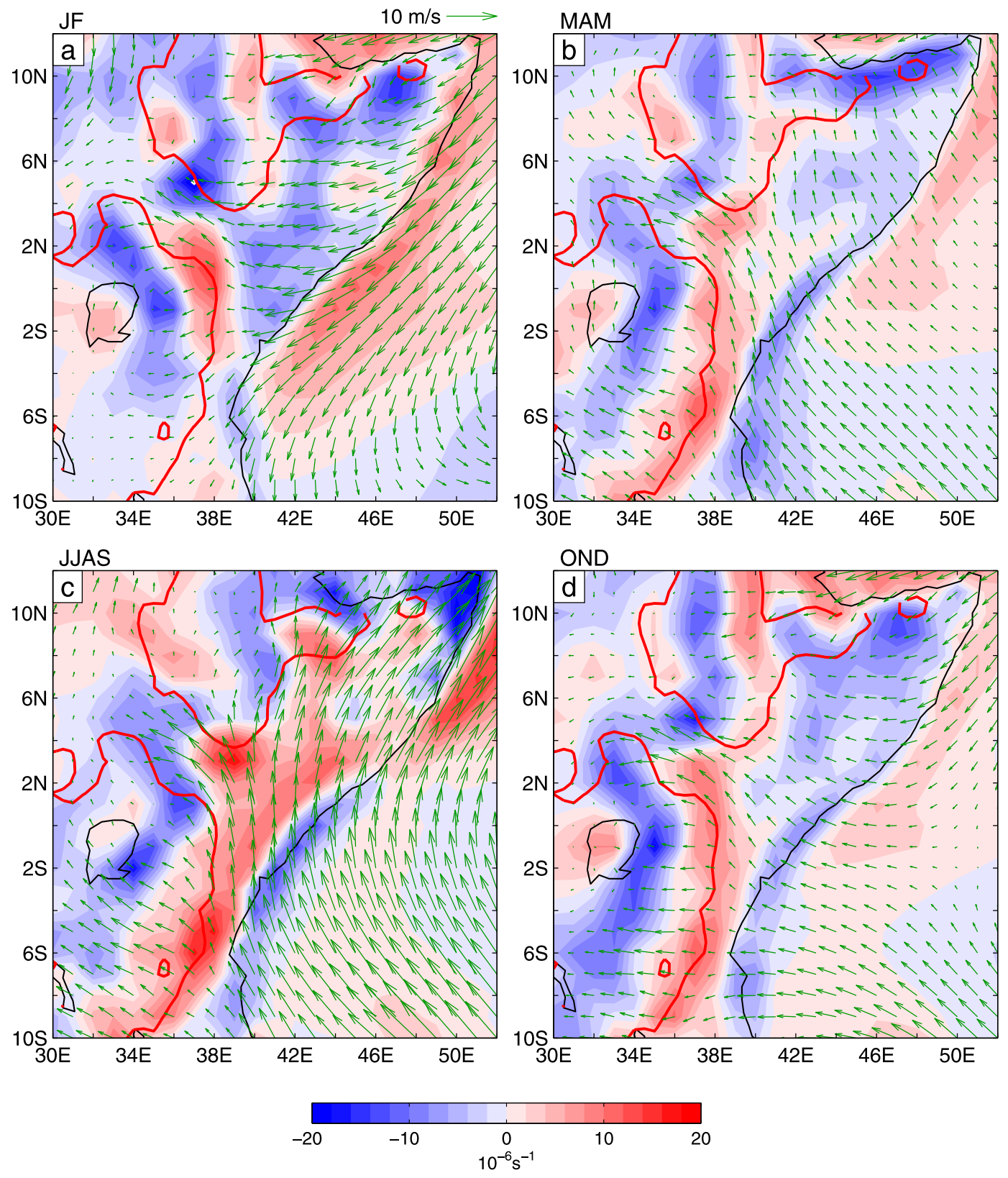

FIG. 11. Seasonal climatologies of the $10-\mathrm{m}$ wind (vectors) and its associated divergence (colors, $10^{-6} \mathrm{~s}^{-1}$ ) from ERA-Interim. The thick red lines show the smoothed 1000-m elevation contours.

$$
P-E=-\frac{1}{g \rho_{w}} \frac{\partial}{\partial t} \int_{0}^{p_{s}} q d p-\frac{1}{g \rho_{w}} \nabla \cdot \int_{0}^{p_{s}} \mathbf{u} q d p
$$

where $P$ is precipitation rate, $E$ is evaporation rate (here understood to include evapotranspiration), $g$ is acceleration due to gravity, $\rho_{w}$ is liquid water density, $p_{s}$ is surface pressure, $q$ is humidity, and $\mathbf{u}$ is horizontal wind velocity. The monthly-mean version of (1), after neglecting the local rate of change term and variations of surface pressure, is

$$
\begin{aligned}
\bar{P}-\bar{E} & \approx-\frac{1}{g \rho_{w}} \nabla \cdot \int_{0}^{p_{s}} \overline{\mathbf{u} q} d p \\
& =-\frac{1}{g \rho_{w}} \nabla \cdot \int_{0}^{p_{s}} \overline{\mathbf{u}} \bar{q} d p-\frac{1}{g \rho_{w}} \boldsymbol{\nabla} \cdot \int_{0}^{p_{s}} \overline{\mathbf{u}^{\prime} q^{\prime}} d p,
\end{aligned}
$$

where the overbars and primes denote the monthly mean and the deviation from the monthly mean, respectively. If we compute a seasonal climatology of the above equation, the final moisture budget equation becomes 

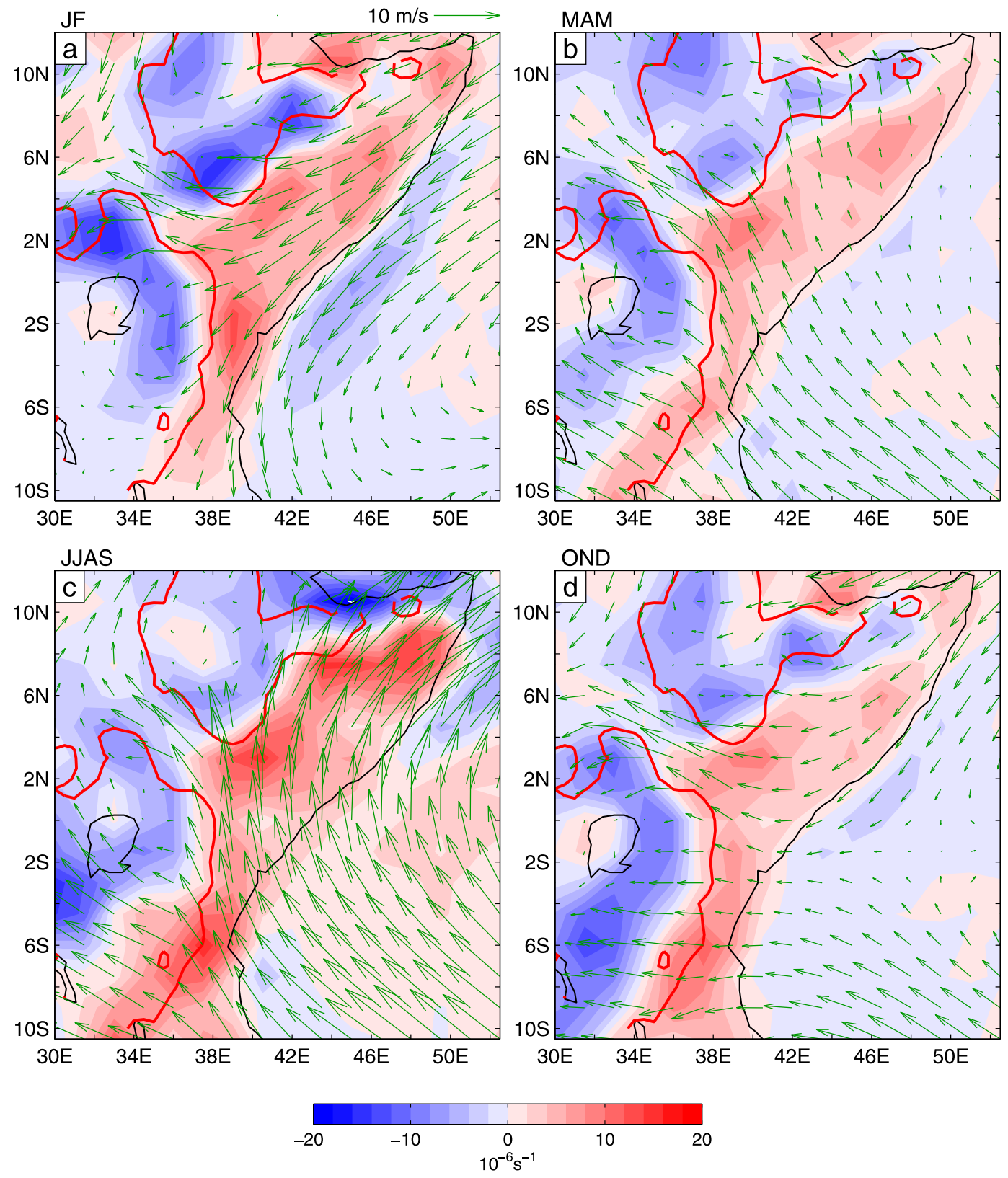

FIG. 12. As in Fig. 11, but at $850 \mathrm{hPa}$.

$$
\begin{aligned}
\overline{\bar{P}}-\overline{\bar{E}} & \approx-\frac{1}{g \rho_{w}} \nabla \cdot \int_{0}^{p_{s}} \overline{\overline{\mathbf{u}}} \bar{q} d p-\frac{1}{g \rho_{w}} \nabla \cdot \int_{0}^{p_{s}} \overline{\overline{\mathbf{u}^{\prime} q^{\prime}}} d p \\
& =-\frac{1}{\rho_{w}} \nabla \cdot \mathrm{VI}_{\mathrm{qmum}}-\frac{1}{\rho_{w}} \nabla \cdot \mathrm{VI}_{\mathrm{qpup}} \\
& =-\mathrm{DVI}_{\mathrm{qmum}}-\mathrm{DVI}_{\mathrm{qpup}},
\end{aligned}
$$

where

$$
\mathrm{VI}_{\mathrm{qmum}}=\frac{1}{g} \int_{0}^{p_{s}} \overline{\overline{\mathbf{u}}} \bar{q} d p,
$$

$$
\begin{aligned}
\mathrm{VI}_{\mathrm{qpup}} & =\frac{1}{g} \int_{0}^{p_{s}} \overline{\overline{\mathbf{u}^{\prime} q^{\prime}}} d p, \\
\mathrm{DVI}_{\mathrm{qmum}} & =\frac{1}{g \rho_{w}} \boldsymbol{\nabla} \cdot \int_{0}^{p_{s}} \overline{\overline{\mathbf{u}} \bar{q}} d p, \quad \text { and } \\
\mathrm{DVI}_{\text {qpup }} & =\frac{1}{g \rho_{w}} \nabla \cdot \int_{0}^{p_{s}} \overline{\overline{\mathbf{u}^{\prime} q^{\prime}}} d p,
\end{aligned}
$$

and the top overbar denotes seasonal climatology. Here $\mathrm{VI}_{\mathrm{qmum}}$ and $\mathrm{VI}_{\mathrm{qpup}}$ represent the seasonal climatologies 


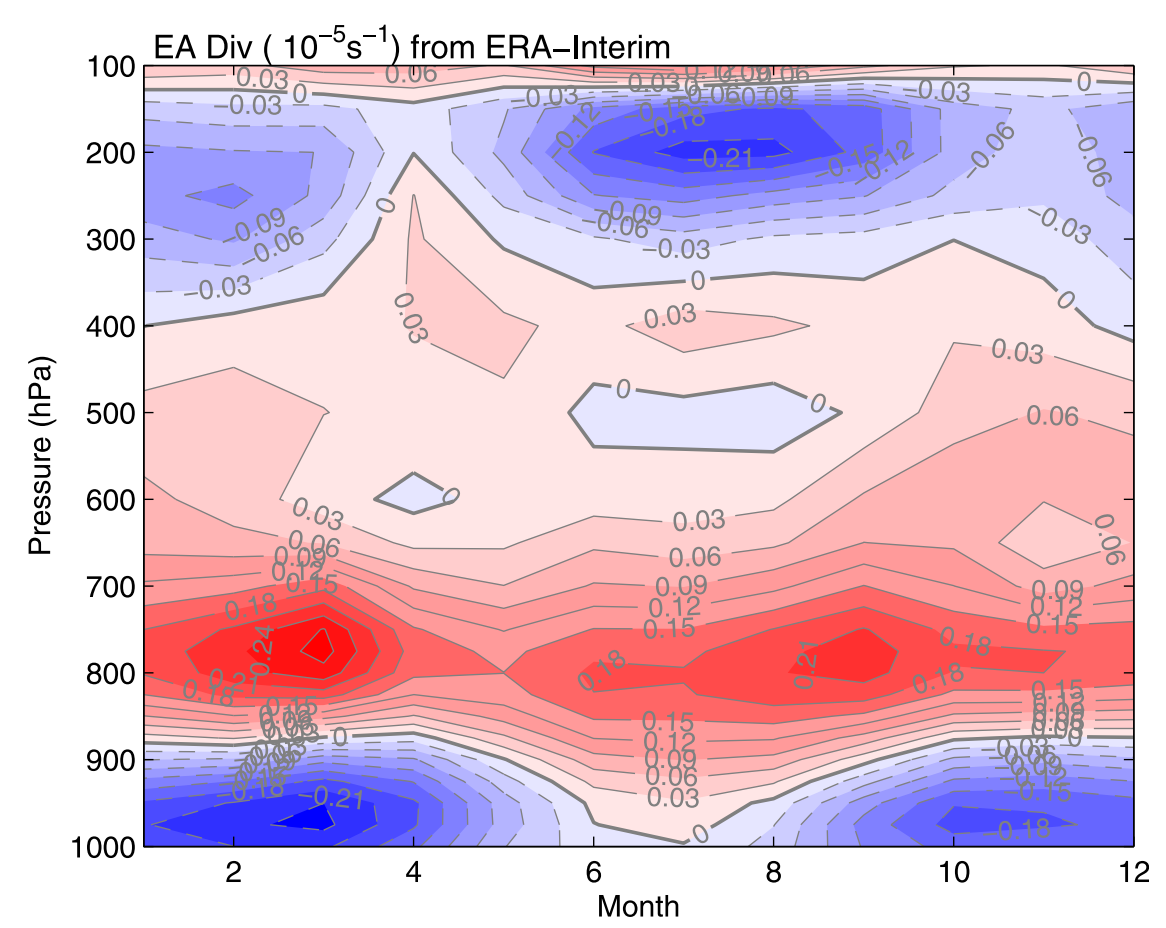

FIG. 13. Annual cycles of wind divergence averaged over the shaded area shown in Fig. 4.

of the vertically integrated moisture flux due to monthly-mean circulation and submonthly eddies, respectively, with $\mathrm{DVI}_{\mathrm{qmum}}$ and $\mathrm{DVI}_{\mathrm{qpup}}$ being the corresponding divergences. In these names, the subscripts "qm" and "um" denote monthly-mean specific humidity and circulation, while subscripts "qp" and "up" represent deviations from their monthly means. These terms were evaluated in ERA-Interim as in Seager and Henderson (2013) and the notations-naming conventions are also briefly described in http://kage.ldeo. columbia.edu/naomi/notation.pdf.

Figure 16 shows the seasonal climatologies of $\mathrm{VI}_{\mathrm{qmum}}$ ( $\mathrm{VI}_{\mathrm{qpup}}$ has much smaller magnitude than $\mathrm{VI}_{\mathrm{qmum}}$ and its map is not shown here). These fluxes in general follow the pattern of the low-level circulation (Fig. 12) as most of the moisture in the atmosphere is concentrated within the bottom layer. The estimated net moisture transport from the Indian Ocean through the East African coast noted in Fig. 16 (sum of the three terms) is much greater during the rainy seasons than the dry seasons, consistent with the precipitation annual cycle in this region. The net transport is low in JF (Fig. 16a) because the moisture flux is almost parallel to the coast in this season while during summer strong moisture flux out into the Indian Ocean across the northeastern coast is responsible for the lowest net moisture import into East Africa (Fig. 16c).

We also assess the relative importance of the circulation annual cycle and humidity annual cycle in the annual cycle of total moisture transport from the Indian Ocean into East Africa by estimating the moisture transport with four different combinations of $q, u$, and $v$ : 1) monthly-mean $q, u$, and $v$;2) monthly-mean $u$ and $v$ and annual mean $q$ (to assess the importance of the circulation annual cycle);3) monthly-mean $q$ and annual mean $u$ and $v$ (to estimate the importance of the humidity annual cycle); and 4) annual mean $q$, $u$, and $v$ (the base component without an annual cycle). With the last combination estimated as $190 \times 10^{6} \mathrm{~kg} \mathrm{~s}^{-1}$, the results of the first three combinations, after the base component is removed, are shown in Fig. 17. The moisture transport estimation based on monthly-mean $q, u$, and $v$ (red bars) is consistent with the precipitation annual cycle over East Africa as shown before, with higher values in rainy seasons than in dry seasons. Meanwhile, both the component associated with the circulation annual cycle (green bars) and the component associated with the humidity annual cycle (blue bars) follow the total moisture transport but the magnitude of the former is at least 2 times larger than that of the latter. This implies that the circulation annual cycle is more important than the humidity annual cycle in the annual cycle of moisture transport from Indian Ocean into East Africa.

Figure 18 shows the annual cycles of the different terms in the moisture budget equation averaged over East Africa. The precipitation from ERA-Interim (the green dashed line) is able to capture the annual cycle of 

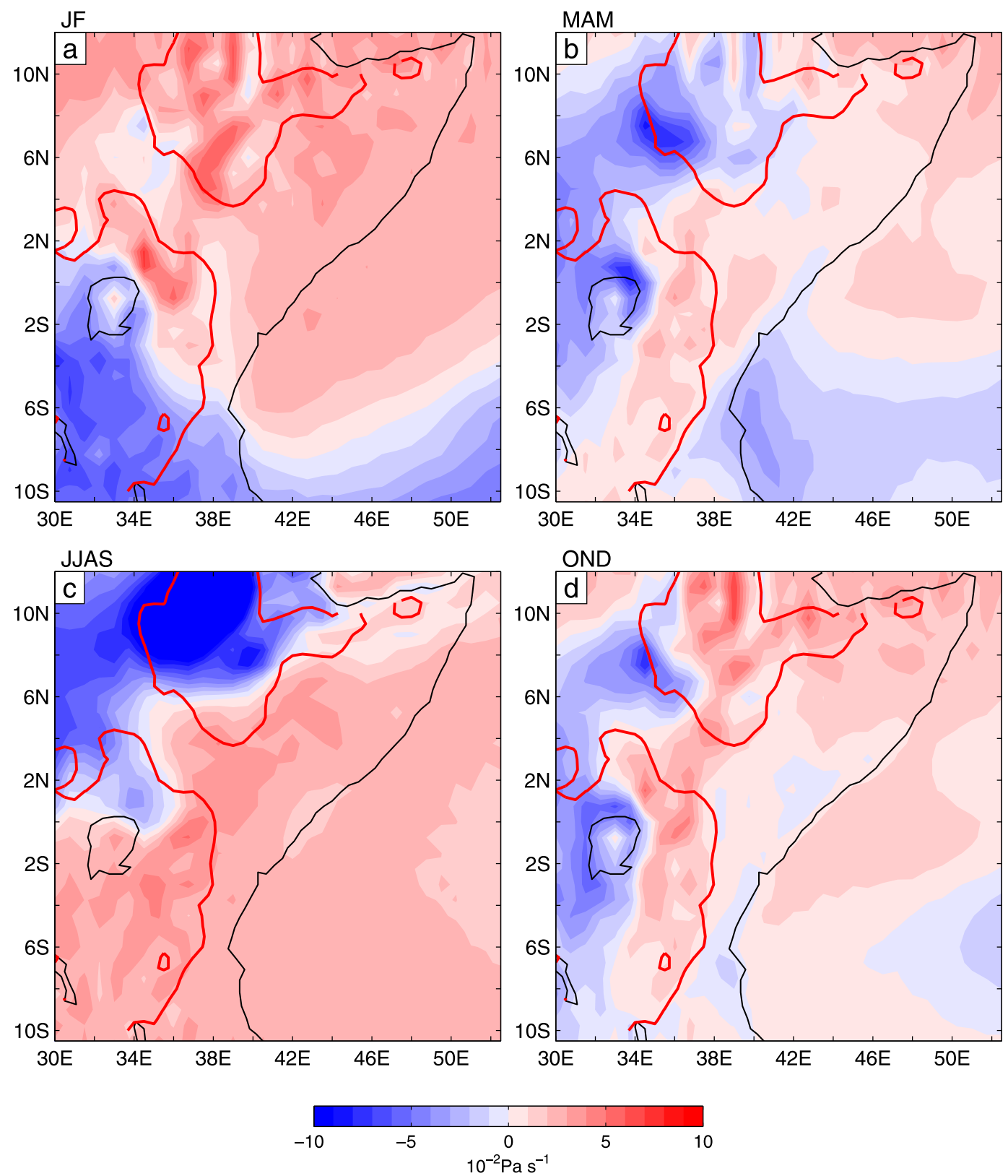

FIG. 14. Seasonal climatologies of 500-hPa vertical pressure velocity $(\omega)$ from ERA-Interim. The thick red lines show the smoothed $1000-\mathrm{m}$ elevation contours.

the GPCC data (the green solid line) although it also has the problem of overestimating the magnitude of the short rains. Evaporation has comparable magnitude to the precipitation but much weaker season-to-season variations. The divergence of the vertically integrated moisture flux can be decomposed into the component associated with the monthly-mean flow and moisture $\left(\mathrm{DVI}_{\mathrm{qmum}}\right)$ and the component due to submonthly eddies $\left(\mathrm{DVI}_{\mathrm{qpup}}\right)$. There is mean flow moisture divergence, indicating atmospheric exportation of moisture in all months except in April and October. The eddy component $\mathrm{DVI}_{\mathrm{qpup}}$ is much weaker and out of phase with the mean flow component. It should be noted here that the annual mean $E$ is much greater than the annual mean precipitation either from GPCC or from ERA-Interim, which was also found in previous studies and usually attributed to extensions of oceanic $P-E$ patterns near coasts due to the models' low resolution (Dai and Trenberth 2002). As our focus here is primarily on the annual cycle instead of the annual mean 


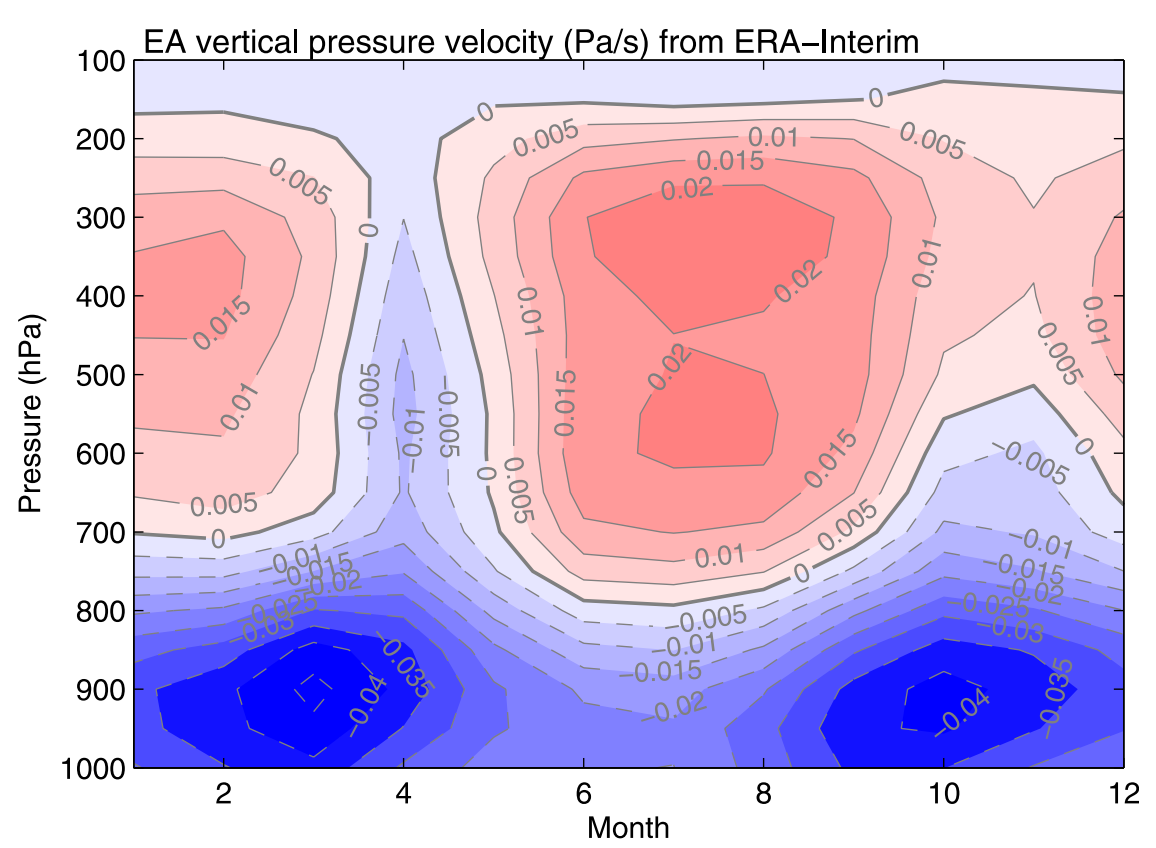

FIG. 15. Annual cycles of vertical pressure velocity $(\omega)$ from ERA-Interim averaged over the shaded area shown in Fig. 4.

climatology, this is not a big problem. The sum of the three components ( $E$, the mean and transient flow moisture convergence, the gray line) approximates the precipitation annual cycle very well, especially for the GPCC data (correlation coefficient 0.94). These results demonstrate that the moisture budget analysis does a good job in East Africa in terms of annual cycle. Figure 18 also shows that the two seasonal precipitation peaks are driven by the two periods of mean flow moisture convergence, which are themselves driven by the two peaks in low-level mean flow mass convergence. The seasonal cycle of the area mean moisture convergence is in turn related to that of the moisture transport across the East Africa coast.

\section{Conclusions and discussion}

Recent studies have demonstrated that coupled models used in CMIP phases 3 and 5 generally misrepresent the East African precipitation annual cycle by overestimating the short rains (rainfall in OND) (Yang et al. 2014), which casts doubt on the reliability of projections of future East African precipitation (Waithaka et al. 2013). To understand the discrepancy between the model simulations and observations in this regard, a natural first step is to better understand the observed East African precipitation annual cycle. By using ERAInterim data, we have analyzed the seasonal climatologies and annual cycles of atmospheric thermal condition, circulation, and moisture budget, which are closely related to the East African precipitation annual cycle. The following conclusions have been reached:

- The off-coast SST (i.e., the western Indian Ocean SSTs) annual cycle is closely related to that for East African precipitation. These SSTs are higher during the rainy seasons than in the dry seasons and are highest during the long rains.

- The atmosphere is generally conditionally stable throughout the year but the degree of instability measured as the difference between surface MSE and the saturated MSE at $700 \mathrm{hPa}$ follows the precipitation annual cycle, that is, less stable during the rainy seasons and more stable during the dry seasons and least stable during the long rains season.

- The annual cycle of the atmospheric stability is dominated by the surface MSE, and, in particular, by the annual cycle of surface humidity.

- Although convergence prevails very near the surface, divergence in the low-level troposphere and convergence in the upper-level troposphere dominate yearround.

- Consistent with the divergence field, the vertical velocity is predominantly downward in the middle troposphere and the magnitude is stronger in dry seasons than in rainy seasons.

- The vertically integrated moisture flux is dominated by the monthly-mean component with the submonthly eddy component much weaker. The total cross-coast 

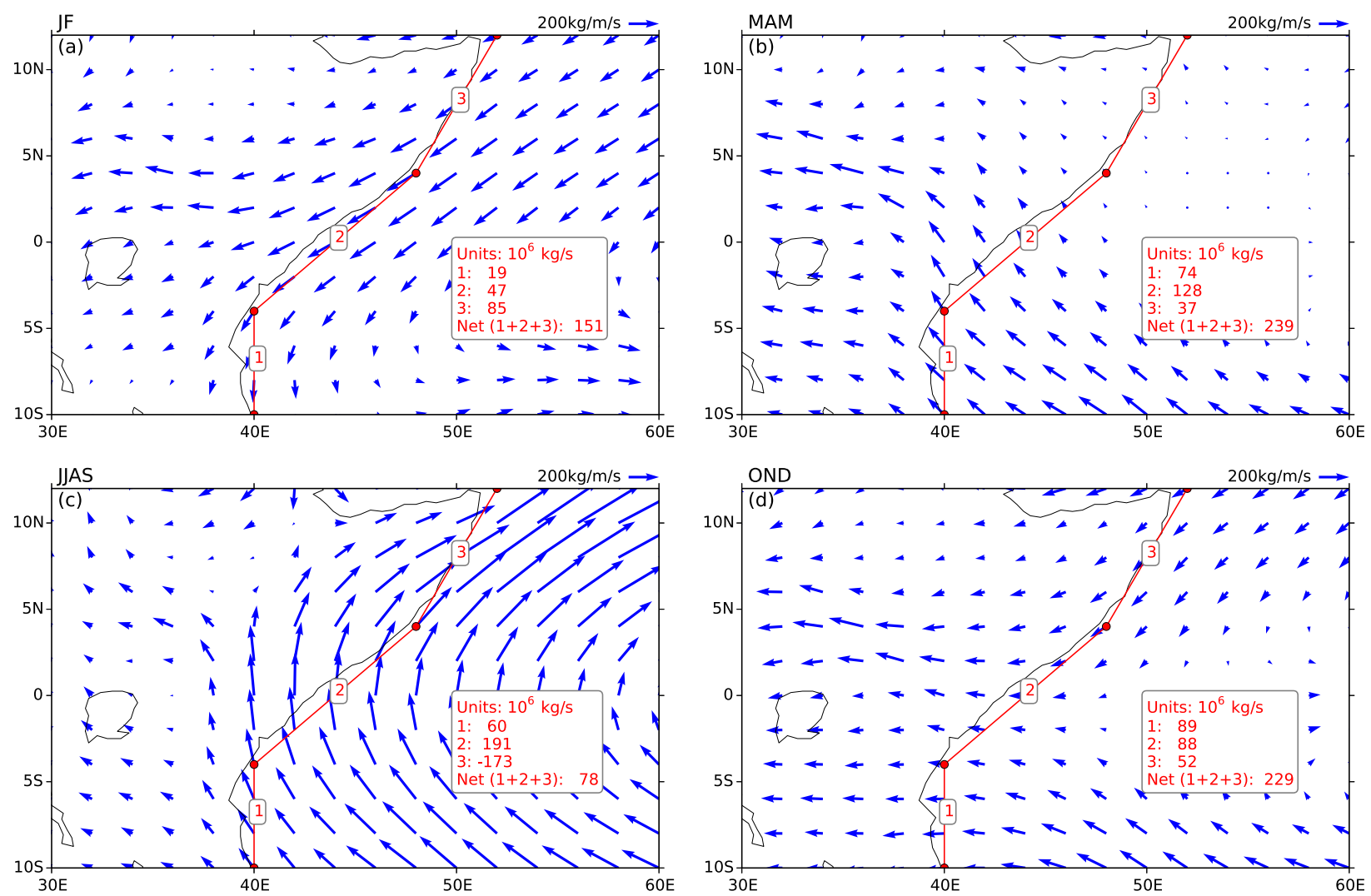

FIG. 16. Seasonal climatologies of the vertically integrated moisture flux of the monthly circulation and humidity from ERA-Interim. The stepwise numbered red lines approximate the coast and the moisture transports [westward (eastward) transports are positive (negative)] through these lines are listed in the box to the right.

moisture transport from the Indian Ocean into East Africa follows the precipitation annual cycle in this region. The annual cycle of this transport is primarily due to the circulation annual cycle and the role of the humidity annual cycle is secondary but modifying.

- The area-averaged mean flow moisture convergence follows the East African precipitation annual cycle and, when combined with the transient eddy convergence and evaporation $(E)$, approximates the observed East African precipitation annual cycle very well.

The region of East Africa, while in the deep tropics and surrounded by the world's major monsoons (the South Asian monsoon, the West African monsoon, and the Australian monsoon), does not exhibit either a wet climate in terms of annual mean precipitation or a monsoonal climate in terms of precipitation annual cycle. Instead, East Africa is dominated by a semiarid/ arid climate with a bimodal annual cycle of precipitation. Traditionally, the aridity was considered to be associated with the dominant low-level divergence (Trewartha 1961), which in turn was assumed to be caused by a wind stress contrast between land and ocean (Nicholson 1996). However, the wind stress mechanism would be greatest near the surface and along immediate coastal areas. Our results (Fig. 11) show that the surface winds are mostly convergent along the east coast while the 850 -hPa winds are predominantly divergent over much of the region to the east of the highlands (Fig. 12). This is in contrast to the wind stress mechanism.

So what mechanism might be responsible for the semiarid/arid climate in East Africa? Unlike extratropical precipitation, which is mainly driven by synoptic-scale baroclinic eddies (Lee and Held 1993; Pierrehumbert and Swanson 1995; Chang et al. 2002; Yang et al. 2007), tropical rainfall mostly arises from moist convection, in which the subcloud MSE plays a key role in the framework of quasi-equilibrium (QE; Emanuel et al. 1994). The QE framework has been applied to study the mechanisms that limit the poleward extent of summer monsoons (Chou and Neelin 2001, 2003), the location of monsoons (Privé and Plumb 2007a,b), and the role of orography in monsoons (Boos and Kuang 2010). An important and relevant idea from these studies is that ventilation (which was defined as the 


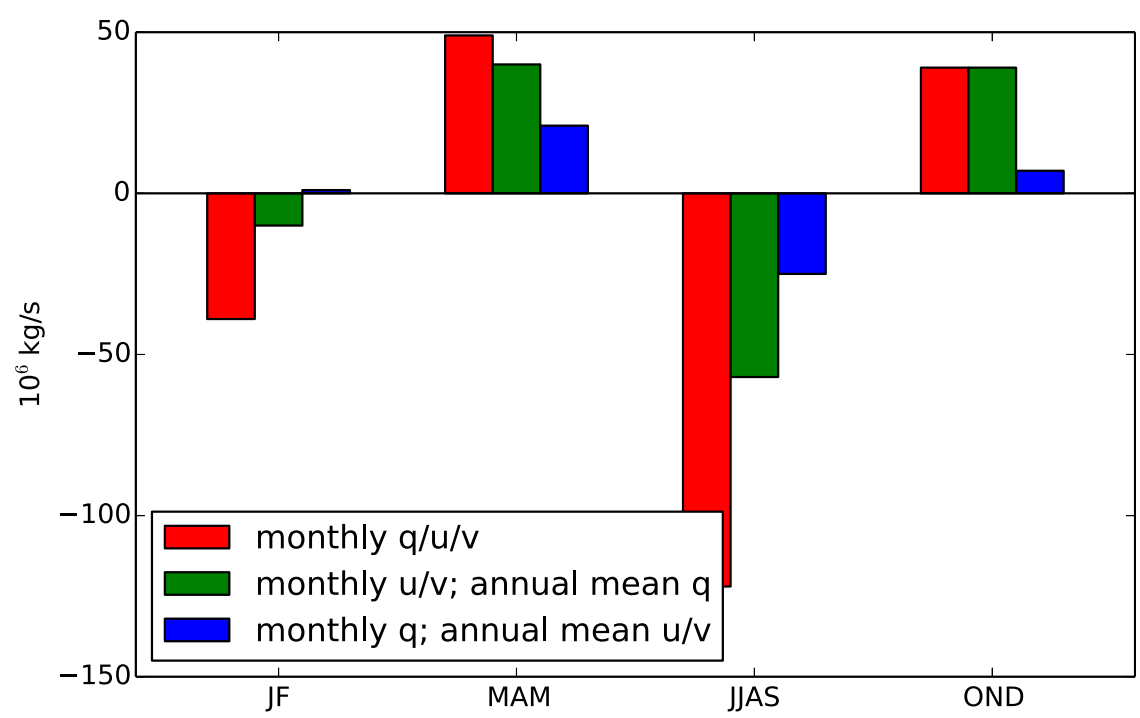

FIG. 17. Vertically integrated moisture transports from the Indian Ocean into East Africa through the coast between $10^{\circ} \mathrm{S}$ and $12^{\circ} \mathrm{N}$ in the four seasons (the annual mean $q, u$, and $v$ component, which is estimated as $190 \times 10^{6} \mathrm{~kg} \mathrm{~s}^{-1}$, has been removed to emphasize the annual cycle). Different colors show results from different cases with red bars using monthly-mean $q, u$, and $v$, green bars using annual mean $q$ and monthly-mean $u$ and $v$, and blue bars using annual mean $u$ and $v$ and monthly-mean $q$.

import of low MSE air by advection from cooler oceans) depresses local convection and precipitation by decreasing the subcloud MSE. It should be noted that the ventilation mechanism in these studies is generally applied only in the subtropical margins of convection zones because of drier and cooler air to the poleward side. However, in the case of East Africa, there are strong low-level cross-equatorial monsoonal winds during the dry seasons, especially in summer, which can bring much lower MSE air from the winter hemisphere into East Africa and stabilize the atmosphere. The north-south-oriented highlands act to block the import of high MSE air from the west as well as leading to the formation of the East African low-level jet (Findlater 1969). Indeed, numerical experiments without topography (Fig. 1a in Chou and Neelin 2003) demonstrated that East Africa is much wetter during the boreal summer season due to the fact that the low-level jet in observations is now replaced by westerlies in the simulation, which bring high MSE air from the interior of Africa to the west. Furthermore, SSTs near the coast are generally cool compared to values further offshore

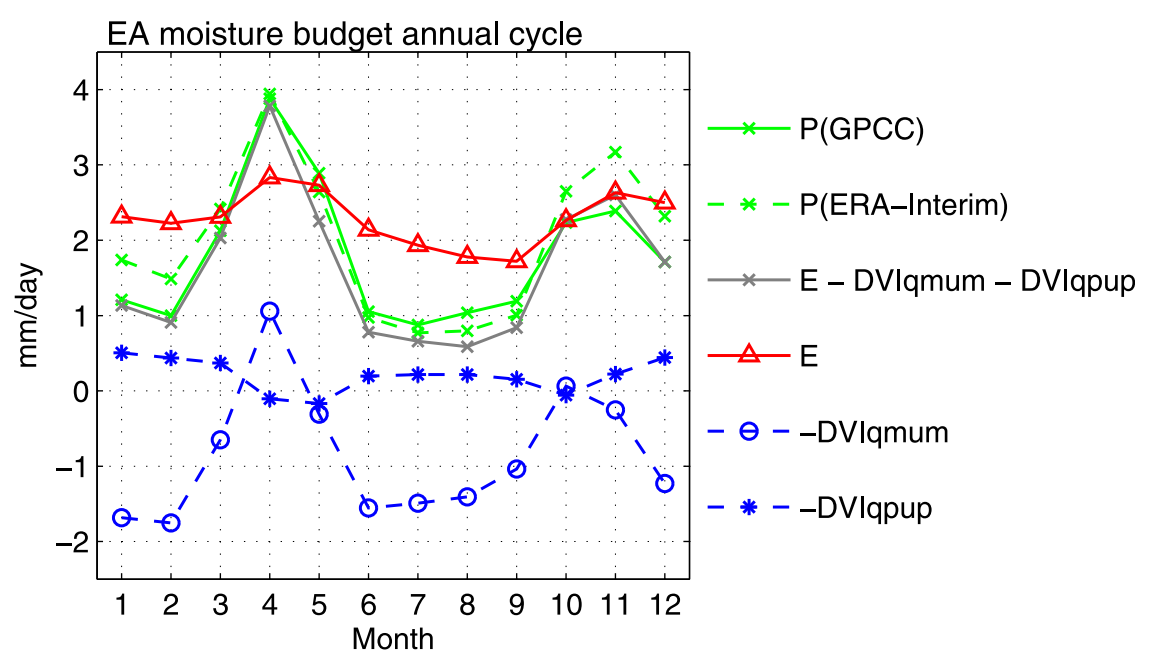

FIG. 18. Annual cycles of the moisture budget terms averaged over the areas shown in Fig. 4 from ERA-Interim. 
(Fig. 5) and a cool west-warm east SST gradient off the coast exists year-round. Therefore, even in the rainy seasons when the air is imported from the western tropical Indian Ocean by the weak onshore winds, it is still difficult for East Africa to develop as high subcloud MSE as in regions with high coastal SSTs. Since the saturated MSE above the boundary layer is nearly uniform across the tropics (Sobel et al. 2001), and influenced by the warmest of tropical regions, low subcloud MSE in East Africa ensures overwhelming stable conditions to moist convection.

The bimodal annual cycle is therefore proposed to be the result of the annual cycle of monsoonal winds combining with the annual cycle of the Indian Ocean SST. During boreal winter precipitation over East Africa is suppressed due to advection of low-MSE air from the cold northern Indian Ocean. During boreal summer the precipitation is suppressed due to even stronger advection from the cool Indian Ocean with the cool Indian Ocean resulting from both winds coming from the winter hemisphere and the coastal upwelling associated with the Somali jet. During the two rainy seasons, the low-level winds are much weaker and thus have less impact on the surface air MSE over East Africa. Moreover, the SSTs off the coast are higher during the two rainy seasons and are the highest of the year during the long rains season. These are the reasons, we propose, why there is more precipitation during the two rainy seasons and the long rains are stronger than the short rains. For all seasons, the off-coast SSTs are still lower than that of the eastern interior of the Indian Ocean (i.e., there is a west-east SST gradient over the Indian Ocean within the East African latitudes). The cooler SSTs off the East African coast, when combined with the year-round onshore winds, prevent land areas over East Africa from developing high subcloud MSE and therefore suppress the overall precipitation in this region. This would explain the largely semiarid-arid climate over East Africa.

Recent studies demonstrated that simulations from coupled climate models tend to have a west-east SST gradient that is too weak; that is, simulated SST over the western Indian Ocean (including the SST nearby the East African coast) is higher than observed while the eastern Indian Ocean SST is close to or lower than observed. This is especially so during the boreal late autumn-early winter months (Conway et al. 2007; Han et al. 2012; Liu et al. 2014; Cai and Cowan 2013). This might be one of the reasons why coupled models generally have a tendency to overestimate the short rains. We will next look at SSTs as well as circulation patterns in those CMIP coupled models that are crucial in the East African subcloud MSE development and moisture flux in order to better understand the overestimation of the short rains in coupled models and the consequent misrepresentation of the East African annual cycle of precipitation. This understanding should lead to improvements in the model representation, which could further lead to greater confidence in model projections of future East African climate.

Acknowledgments. This work was supported by NOAA Award NA10OAR4310137 (Global Decadal Hydroclimate Variability and Change). Funding for BL was provided by the National Science Foundation under award AGS 12-52301. We thank the two anonymous reviewers for their helpful suggestions and comments.

\section{REFERENCES}

Anyah, R. O., and W. Qiu, 2012: Characteristic 20th and 21st century precipitation and temperature patterns and changes over the Greater Horn of Africa. Int. J. Climatol., 32, 347-363, doi:10.1002/joc.2270.

Berrisford, P., P. Kållberg, S. Kobayashi, D. Dee, S. Uppala, A. J. Simmons, P. Poli, and H. Sato, 2011: Atmospheric conservation properties in ERA-Interim. Quart. J. Roy. Meteor. Soc., 137, 1381-1399, doi:10.1002/qj.864.

Boos, W., and Z. Kuang, 2010: Dominant control of the South Asian monsoon by orographic insulation versus plateau heating. Nature, 463, 218-222, doi:10.1038/nature08707.

Cai, W., and T. Cowan, 2013: Why is the amplitude of the Indian Ocean dipole overly large in CMIP3 and CMIP5 climate models? Geophys. Res. Lett., 40, 1200-1205, doi:10.1002/ grl.50208.

Chang, E. K., S. Lee, and K. L. Swanson, 2002: Storm track dynamics. J. Climate, 15, 2163-2183, doi:10.1175/1520-0442(2002)015<02163: $\mathrm{STD}>2.0 . \mathrm{CO} ; 2$.

Chou, C., and J. D. Neelin, 2001: Mechanisms limiting the southward extent of the South American summer monsoon. Geophys. Res. Lett., 28, 2433-2436, doi:10.1029/ 2000GL012138.

— and - 2003: Mechanisms limiting the northward extent of the northern summer monsoons over North America, Asia, and Africa. J. Climate, 16, 406-425, doi:10.1175/ 1520-0442(2003)016<0406:MLTNEO > 2.0.CO;2.

Conway, D., C. Hanson, R. Doherty, and A. Persechino, 2007: GCM simulations of the Indian Ocean dipole influence on East African rainfall: Present and future. Geophys. Res. Lett., 34, L03705, doi:10.1029/2006GL027597.

Cook, B. I., and R. Seager, 2013: The response of the North American monsoon to increased greenhouse gas forcing. J. Geophys. Res. Atmos., 118, 1690-1699, doi:10.1002/jgrd.50111.

Cook, K. H., and E. K. Vizy, 2013: Projected changes in East African rainy seasons. J. Climate, 26, 5931-5948, doi:10.1175/ JCLI-D-12-00455.1.

Dai, A., and K. Trenberth, 2002: Estimates of freshwater discharge from continents: Latitudinal and seasonal variations. J. Hydrometeor., 3, 660-687, doi:10.1175/1525-7541(2002)003<0660: EOFDFC $>2.0 . \mathrm{CO} ; 2$.

Dee, D., and Coauthors, 2011: The ERA-Interim reanalysis: Configuration and performance of the data assimilation system. Quart. J. Roy. Meteor. Soc., 137, 553-597, doi:10.1002/qj.828.

Emanuel, K., J. David Neelin, and C. Bretherton, 1994: On largescale circulations in convecting atmospheres. Quart. J. Roy. Meteor. Soc., 120, 1111-1143, doi:10.1002/qj.49712051902. 
FEWS NET, 2011: East Africa: Past year one of the driest on record in the eastern Horn. Famine Early Warning System Network Rep. [Available online at http://reliefweb.int/report/ ethiopia/east-africa-past-year-one-driest-record-eastern-hornjune-14-2011.]

Findlater, J., 1969: A major low-level air current near the Indian Ocean during the northern summer. Quart. J. Roy. Meteor. Soc., 95, 362-380, doi:10.1002/qj.49709540409.

Han, Z.-Y., T.-J. Zhou, and L.-W. Zou, 2012: Indian Ocean SST biases in a Flexible Regional Ocean Atmosphere Land System (FROALS) model. Atmos. Oceanic Sci. Lett., 5, 273-279.

Held, I., and B. Soden, 2006: Robust responses of the hydrological cycle to global warming. J. Climate, 19, 5686-5699, doi:10.1175/ JCLI3990.1.

Huffman, G. J., R. F. Adler, D. T. Bolvin, and G. Gu, 2009: Improving the global precipitation record: GPCP version 2.1. Geophys. Res. Lett., 36, L17808, doi:10.1029/2009GL040000.

Karnauskas, K., R. Seager, A. Giannini, and A. Busalacchi, 2013: A simple mechanism for the climatological midsummer drought along the Pacific coast of Central America. Atmósfera, 26, 261-281.

Kinuthia, J. H., 1992: Horizontal and vertical structure of the Lake Turkana jet. J. Appl. Meteor., 31, 1248-1274, doi:10.1175/ 1520-0450(1992)031<1248:HAVSOT $>2.0$.CO;2.

— (Turkana Channel). Mon. Wea. Rev., 110, 1722-1728, doi:10.1175/1520-0493(1982)110<1722:ANFJIN>2.0.CO;2.

Laîné, A., H. Nakamura, K. Nishii, and T. Miyasaka, 2014: A diagnostic study of future evaporation changes projected in CMIP5 climate models. Climate Dyn., 42, 2745-2761, doi:10.1007/s00382-014-2087-7.

Lee, S., and I. M. Held, 1993: Baroclinic wave packets in models and observations. J. Atmos. Sci., 50, 1413-1428, doi:10.1175/ 1520-0469(1993)050<1413:BWPIMA $>2.0 . C O ; 2$.

Liu, L., S.-P. Xie, X.-T. Zheng, T. Li, Y. Du, G. Huang, and W.-D. Yu, 2014: Indian Ocean variability in the CMIP5 multi-model ensemble: The zonal dipole mode. Climate Dyn., 43, 17151730, doi:10.1007/s00382-013-2000-9.

Lyon, B., 2014: Seasonal drought in the Greater Horn of Africa and its recent increase during the March-May long rains. J. Climate, 27, 7953-7975, doi:10.1175/JCLI-D-13-00459.1.

—, and D. G. DeWitt, 2012: A recent and abrupt decline in the East African long rains. Geophys. Res. Lett., 39, L02702, doi:10.1029/2011GL050337.

_- A. Barnston, and D. G. DeWitt, 2014: Tropical Pacific forcing of a 1998-1999 climate shift: Observational analysis and climate model results for the boreal spring season. Climate Dyn., 43, 893-909, doi:10.1007/s00382-013-1891-9.

McCreary, J. P., P. K. Kundu, and R. L. Molinari, 1993: A numerical investigation of dynamics, thermodynamics and mixed-layer processes in the Indian Ocean. Prog. Oceanogr., 31, 181-244, doi:10.1016/0079-6611(93)90002-U.

Murtugudde, R., R. Seager, and A. Busalacchi, 1996: Simulation of the tropical oceans with an ocean GCM coupled to an atmospheric mixed-layer model. J. Climate, 9, 1795-1815, doi:10.1175/ 1520-0442(1996)009<1795:SOTTOW $>2.0 . C O ; 2$.

,$- \ldots$, and P. Thoppil, 2007: Arabian Sea response to monsoon variations. Paleoceanography, 22, PA4217, doi:10.1029/ 2007 PA001467.

Nicholson, S. E., 1996: A review of climate dynamics and climate variability in eastern Africa. The Limnology, Climatology and Paleoclimatology of the East African Lakes, T. C. Johnson and E. O. Odada, Eds., Gordon and Breach, 25-56.

_ 2011: Dryland Climatology. Cambridge University Press, 528 pp.
Pierrehumbert, R., and K. Swanson, 1995: Baroclinic instability. Annu. Rev. Fluid Mech., 27, 419-467, doi:10.1146/ annurev.fl.27.010195.002223.

Privé, N. C., and R. A. Plumb, 2007a: Monsoon dynamics with interactive forcing. Part I: Axisymmetric studies. J. Atmos. Sci., 64, 1417-1430, doi:10.1175/JAS3916.1.

$\longrightarrow$, and $-2007 \mathrm{~b}$ : Monsoon dynamics with interactive forcing. Part II: Impact of eddies and asymmetric geometries. J. Atmos. Sci., 64, 1431-1442, doi:10.1175/JAS3917.1.

Rudolf, B., A. Becker, U. Schneider, A. Meyer-Christoffer, and M. Ziese, 2010: The new "GPCC Full Data Reanalysis Version 5" providing high-quality gridded monthly precipitation data for the global land-surface is public available since December 2010. GPCC Status Rep. (December), 7 pp. [Available online at http://www.dwd.de/bvbw/generator/DWDWWW/Content/ Oeffentlichkeit/KU/KU4/KU42/en/Reports__Publications/ GPCC__status__report__2010,templateId=raw,property= publicationFile.pdf/GPCC_status_report_2010.pdf.]

Schneider, E. K., 1996: A note on the annual cycle of sea surface temperature at the equator. COLA Rep. 36,18 pp.

Seager, R., and N. Henderson, 2013: Diagnostic computation of moisture budgets in the ERA-Interim reanalysis with reference to analysis of CMIP-archived atmospheric model data. J. Climate, 26, 7876-7901, doi:10.1175/JCLI-D-13-00018.1.

_ , N. Naik, and G. A. Vecchi, 2010: Thermodynamic and dynamic mechanisms for large-scale changes in the hydrological cycle in response to global warming. J. Climate, 23, 4651-4668, doi:10.1175/2010JCLI3655.1.

Smith, T. M., R. W. Reynolds, T. C. Peterson, and J. Lawrimore, 2008: Improvements to NOAA's historical merged landocean surface temperature analysis (1880-2006). J. Climate, 21, 2283-2296, doi:10.1175/2007JCLI2100.1.

Sobel, A. H., J. Nilsson, and L. M. Polvani, 2001: The weak temperature gradient approximation and balanced tropical moisture waves. J. Atmos. Sci., 58, 3650-3665, doi:10.1175/ 1520-0469(2001)058<3650:TWTGAA > 2.0.CO;2.

Taylor, K. E., R. J. Stouffer, and G. A. Meehl, 2012: An overview of CMIP5 and the experiment design. Bull. Amer. Meteor. Soc., 93, 485-498, doi:10.1175/BAMS-D-11-00094.1.

Trewartha, G. T., 1961: The Earth's Problem Climates. University of Wisconsin Press, 334 pp.

Vizy, E. K., and K. H. Cook, 2012: Mid-twenty-first-century changes in extreme events over northern and tropical Africa. J. Climate, 25, 5748-5767, doi:10.1175/JCLI-D-11-00693.1.

Waithaka, M., G. C. Nelson, T. S. Thomas, and M. Kyotalimye, 2013: East African agriculture and climate change. International Food Policy Research Institute Brief 76, 4 pp. [Available online at http://www.ifpri.org/publication/eastafrican-agriculture-and-climate-change.]

Williams, A. P., and C. Funk, 2011: A westward extension of the warm pool leads to a westward extension of the Walker circulation, drying eastern Africa. Climate Dyn., 37, 2417-2435, doi:10.1007/s00382-010-0984-y.

Yang, W., J. Nie, P. Lin, and B. Tan, 2007: Baroclinic wave packets in an extended quasigeostrophic two-layer model. Geophys. Res. Lett., 34, L05822, doi:10.1029/2006GL029077.

_ R. Seager, and M. A. Cane, 2013: Zonal momentum balance in the tropical atmospheric circulation during the global monsoon mature months. J. Atmos. Sci., 70, 583-599, doi:10.1175/JAS-D-12-0140.1.

, - — - _ and B. Lyon, 2014: The East African long rains in observations and models. J. Climate, 27, 7185-7202, doi:10.1175/JCLI-D-13-00447.1. 